\title{
YANACONAS DEL RAYO. REFLEXIONES EN TORNO A LA PRODUCCIÓN DE METALES EN EL ESPACIO SURANDINO (BOLIVIA, SIGLOS XV-XVI)
}

\author{
Pablo Cruz $^{1}$ y Florian Téreygeol ${ }^{2}$
}

\section{* Minas, hornos y metales en el espacio SURANDINO}

\section{Resumen}

Si de manera general en el espacio andino la minería prehispánica se encontraba limitada a la explotación de vetas superficiales o poco profundas, la metalurgia, en cambio, alcanzó un alto desarrollo tecnológico, el cual permitió tanto la elaboración de aleaciones complejas como la fabricación de objetos sofisticados. De manera que la posesión de las minas del Nuevo Mundo por parte de los españoles significó también el encuentro con los metalurgos indígenas cuyos saberes y técnicas les eran en gran parte desconocidos. Y tanto las minas más fértiles como los especialistas en el trabajo del metal se hallaban por entonces concentrados sobre las altas tierras del Qollasuyu. Partiendo de los datos obtenidos en cuatro establecimientos mineros y metalúrgicos localizados en el altiplano boliviano (Berenguela, Potosí, Porco y San Antonio de Lípez), y articulando los mismos con las informaciones brindadas en las fuentes históricas, trataremos aquí algunos aspectos relacionados con la producción de metales en el espacio surandino durante los períodos Inka y de Contacto (siglos XV y XVI).

Palabras claves: minería - metalurgia - período de Contacto - qollas inkas - yanaconas While pre-Hispanic mining in the Andes is generally understood to have been limited to the exploitation of superficial deposits, pre-Hispanic metallurgy reached high levels of technological development. Metallurgical techniques permitted the production of complicated alloys and sophisticated objects. Spanish takeovers of New World mines brought Spaniards into contact with knowledge and techniques unknown to them at the time. These rich mines and the specialists working them were concentrated in the high-altitude lands of Qollasuyu. In this article, we use data obtained from mining and metallurgical sites located in the Bolivian altiplano (Berenguela, Potosi-Porco, San Antonio de Lipez) and cross-reference them with information found in historical sources, in order to address certain aspects of metal production in the southern Andes during the Incan Period and the Period of Contact (XV and XVI centuries).

Key words: mining - metallurg - Period of Contact - qolla's - inca's yanaconas
Los cuantiosos botines acaparados por los conquistadores españoles, producto de expoliaciones y rescates, confirmaron las informaciones obtenidas anteriormente sobre la existencia en el Perú de infinitas fuentes de metales preciosos. A su vez, la desenfrenada codicia de los españoles, manifiesta desde las primeras interacciones con los pueblos indígenas de la costa del Pacífico, corroboraron los mensajes que el Inka Wayna Qhapaq había recibido en sus aposentos de Tumibamba (Ecuador) poco tiempo antes de su muerte, en donde se le anunciaba el inminente arribo en sus dominios de extraños hombres sedientos de brillo metálico. Aun antes del célebre desembarco en Cajamarca, las minas del antiguo Perú ocupaban ya el centro de la empresa colonial en los Andes, y por ende, también el de la resistencia a la fuerza invasora.

Si de manera general en el espacio andino la minería prehispánica concernió principalmente la explotación a cielo abierto de vetas superficiales o poco profundas ${ }^{3}$, la metalurgia, en cambio, alcanzó un alto desarrollo tecnológico que permitió tanto la elaboración de aleaciones complejas como la fabricación de objetos sofisticados. De suerte que la toma en posesión por parte de los españoles de las minas del Nuevo Mundo significó también el encuentro con los especialistas indígenas, cuyos saberes y técnicas metalúrgicas les eran en gran parte desconocidos. Y tanto las minas más fértiles como los especialistas del trabajo del metal se hallaban por entonces concentrados sobre las tierras altas del Qollasuyu, el cuadrante sur del imperio de los inkas. Una región en la cual, tal como lo

Recibido: enero 2013. Aceptado: octubre 2014.

${ }^{1}$ CONICET-Fundandes. Independencia 271, San Salvador de Jujuy (4600), Jujuy, Argentina. E-mail: saxrapablo@gmail.com.

2 CNRS UMR 5060 IRAMAT-LMC. SIS2M LAPA, Bat 637, CEA Saclay, 91191 Gif-sur-Yvette. E-mail: florian.tereygeol@cea.fr 
señalara Berthelot (1978: 950-952), el Inka y el Sol contaban con minas prácticamente en todas las provincias (Figura 1). Según las fuentes históricas, principalmente el tratado del Padre Álvaro Alonso Barba (1640), entre las principales minas de oro explotadas por el Inka se encontraban las de Carabaya, situada en el extremo noreste de la provincia de Puno (Perú), para cuyo laboreo fueron trasladados un importante contingente de mitmaqkuna desde otras regiones. Otros dos importantes yacimientos de oro explotados por los inkas, ambos llamados Chuquiago o Chuquiabo, se encontraban en el territorio de Omasuyos de Pacajes (La Paz), y en el sud de Chichas (río San Juan, Tupiza).

Con respecto al mineral de plata, sin duda los principales yacimientos fueron los de Potosí y Porco, situados en el territorio Qaraqara, los de Berenguela de Pacajes y los de Oruro. Finalmente, entre las principales minas de cobre figuraron las de Curahuara de Pacajes y las de Escapi en las ásperas tierras de los Lípez. Se suman a éstas otro importante número de explotaciones mineras prehispánicas que fueron ocultadas a los españoles, o pasadas por alto por éstos. Tal fue el caso del mismo cerro de Potosí, principal yacimiento de plata del planeta, así como Salinas de Garci Mendoza, Pulacayo, y, posiblemente, San Antonio de Lípez y Corocoro de Pacajes (Caquingora), éste último con importantes depósitos de cobre nativo, únicos en la región.

Es igualmente en el espacio del Qollasuyu donde se encuentran la mayoría de los testimonios materiales de una metalurgia sofisticada, los cuales resultan, incluso, anteriores a la llegada de los inkas. Entre ellos se destaca el sitio de Pulaco5o, situado en la comunidad de Escara en el margen oriental del Salar de Uyuni, donde se encuentra un complejo establecimiento metalúrgico fechado entre los siglos IX y XIII d.C. (Cruz 2010; Lechtman et al. 2012). Otra región donde se desarrolló una metalurgia compleja con anterioridad a los inkas fue el noroeste argentino, espacio donde existe un abultado corpus de objetos muy sofisticados en bronce estañífero, como las campanas ovales y los discos de bronce santamarianos. Estos objetos, entre otros, denotan una alta maestría metalúrgica tanto en lo que refiere a la formación de aleacio-

\footnotetext{
3 A diferencia de la minería colonial, más "subterránea", con accesos, socavones, galerías y espacios de trabajo dispuestos en varios niveles por debajo de la superficie.
}

nes como al vaciado en moldes bivalvos y la técnica de la cera perdida (González 2004).

Entre muchos otros, estos dos ejemplos señalan que la expansión meridional de los inkas no solo habría estado motivada por la procuración de nuevos yacimientos metalíferos, tal como fue sostenido por autores como Raffino (1993), sino también por el encuentro de nuevos saberes y tecnologías metalúrgicas que permitieron no solo el desarrollo de su metalurgia, sino también acrecentar sustancialmente sus repertorios de objetos metá$\operatorname{licos}^{4}$. De manera que fue en relación con esta expansión meridional del Tawantinsuyo, durante el reinado de los últimos soberanos, que la producción de metales entre los inkas alcanzó su mayor desarrollo, multiplicándose las evidencias de actividades mineras y metalúrgicas en prácticamente todas las regiones por ellos colonizadas. Por su envergadura, se destacan los centros minero-metalúrgicos de Potosí y Porco en Bolivia, Viña del Cerro en el norte de Chile, y Quillay en el noroeste argentino. La procuración de nuevas fuentes de metales preciosos fue también una de las razones para que los inkas se expandieran sobre la vertiente y el piedemonte oriental andino, llegando incluso a las tierras bajas aledañas, estableciéndose en sitios como Saipurú en el Chaco Boliviano (Cruz y Guillot 2010). Las informaciones arqueológicas hoy disponibles, sumadas a las descripciones proporcionadas por algunas fuentes, como el padre Álvaro Alonso Barba, señalan para este período una metalurgia especializada y tecnológicamente diversificada en una variedad de hornos de extracción y refinación, entre los cuales se destacan los famosos hornos de viento, las huayrachinas, destinadas a la reducción de plomo argentífero, y probablemente cobre, 5 y los tocochimbos, pequeños hornos de bóveda utilizados para el refinado de metales.

\footnotetext{
4 En este sentido, es posible identificar dos tradiciones tecnológicas en la metalurgia inkaica del cobre, una primera donde predominan objetos laminares producidos en aleaciones de cobre arsenical, y una segunda, más tardía, donde se generalizan el vaciado en molde y las aleaciones de cobre estañífero. Al respecto ver Lechtman (1978).

5 Así lo sugieren las incrustaciones de escoria en fragmentos de hornos metalúrgicos registrados en un contexto asociado con la ocupación inkaica en el sitio de Jirira, sobre la rivera norte del Salar de Uyuni. Tales fragmentos resultaron de hornos tubulares con aperturas de ventilación en sus paredes, semejantes a los restos de huayrachinas registradas en Potosí (Téreygeol y Cruz 2011).
} 


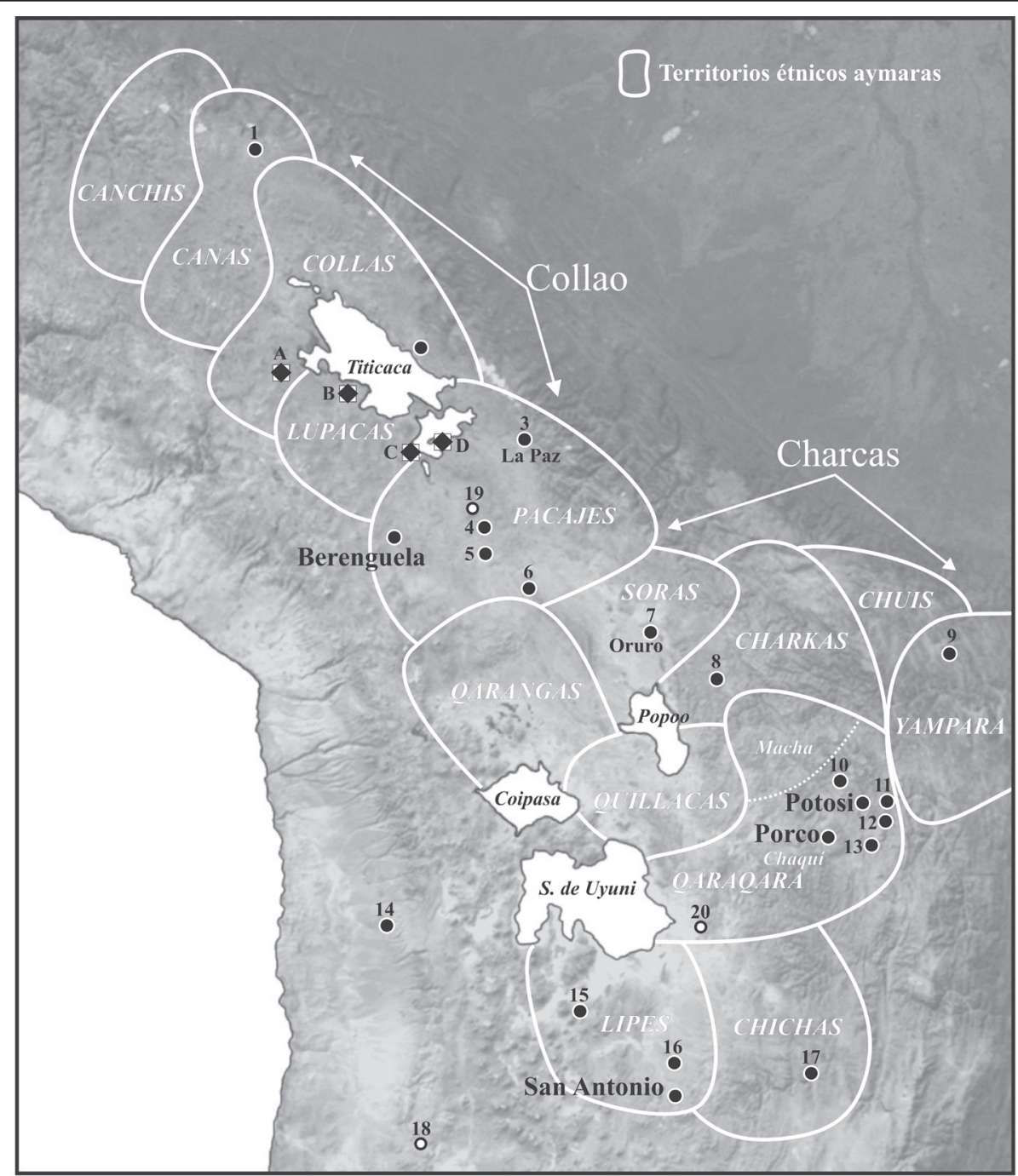

Principales minas prehispánicas señaladas en las fuentes: 1. Carabaya (Au). 2. Carabuco (Sn). 3. Chuquiabo (Au). 4. Caquingora (Ag). 5.Ulloma (Au). 6. Curahuara (Cu). 7. Oruro (Ag). 8. Chayanta (Ag). 9. Quiquijana (Au, Ag). 10. Yocalla (Ag). 11. Chaquí (Ag). 12. Andacaba (Ag). 13. La Lava (Ag). 14. Tarapacá (Ag). 15. Escapi (Cu). 16. Escala (Ag). 17. Río San Juan (Au).

OLocalidades mineras prehispánicas evidenciadas por la arqueología. 18. Calama $(\mathrm{Cu})$. 19. Corocoro (Cu). 20. Pulacayo $(\mathrm{Ag}, \mathrm{Cu})$

Áreas de procedencia del grupo cerámico Qolla Tardío: A. Hatunqolla. B. Juli. C. Desaguadero. D. Taraco.

Figura 1. Mapa con localización de las principales minas en el Qollasuyu.

En cuanto a la producción de metales durante los primeros momentos de la Colonia, la misma puede ser separada en dos momentos o fases: antes y después de los años 1572-1574. En la primera, que se corresponde con el período de Contacto, al ritmo de la Conquista se explotaron en gran escala las antiguas minas indígenas, implementando en ello herramientas de hierro, pólvora, y técnicas extractivas del Viejo Mundo. Sin embargo, la producción metalúrgica continuó reposando sobre una mano de obra y una tecnología indígena (Cruz y Absi 2008) en función 
tanto de la naturaleza de los minerales tratados, como de las encrucijadas políticas y pugnas de poder entre los propios españoles, los inkas y los pueblos indígenas locales. En un contexto de ensayos y transferencias de tecnologías, en la región de Potosí las antiguas huayras indígenas fueron estandarizadas, construyendo las mismas a partir de un ensamble de segmentos prefabricados que facilitó su transporte hacia los sitios de fundición (Figura 2). De la misma manera, los hornos de reverbero europeos fueron adaptados al medio local incorporando elementos ya conocidos en los Andes (Pulacayo), como una chimenea separada del cuerpo central y las aperturas o conductos de regulación térmica en la cámara, que permitieron un funcionamiento en alturas elevadas sin necesidad de fuelles. Tal es el caso de los hornos de reverbero identificados en Berenguela y Santa Isabel (Figura 3), los cuales muy probablemente remontan al siglo XVII, como aquellos estudiados en Porco (Van Buren y Cohen 2010) y en la puna de Jujuy (Angiorama y Becerra 2010).

A partir de 1572, varios acontecimientos propulsados por el Virrey Francisco de Toledo cambiaron sustancialmente el modo de producción de metales y, de hecho, el destino de los pueblos indígenas de toda el área. Por un lado, se da muerte a Tupaq Amaru I en 1572 y claudica el mismo año el último enclave de resistencia inkaica en Vilcabamba. Por el otro, se instaura y se generaliza en 1573 en Potosí el proceso tecnológico de amalgamación de la plata por mercurio que remplazaría paulatinamente las antiguas tecnologías metalúrgicas indígenas. Finalmente, se ordenan y se aplican a partir de 1573 una serie de medidas administrativas destinadas a regular tanto las poblaciones indígenas (reducciones) como la producción minera, en la que sobresale la instauración de un sistema a gran escala de relocalización de mano de obra indígena: la mita.

Partiendo de los datos arqueológicos obtenidos en antiguos establecimientos mineros-metalúrgicos del altiplano boliviano, los cuales fueron articulados con informaciones históricas, trataremos aquí sobre algunos aspectos de la producción de metales en los comienzos de la Colonia, donde se remarca la participación de personas oriundas del Collao en la producción de metales. En un primer tiempo trataremos sobre los sitios mineros-metalúrgicos estudiados y sus cronologías. Seguidamente, presentaremos y analizaremos los datos arqueológicos y las informaciones históricas que señalan la participación de los pueblos "qollas" en las minas y centros metalúrgicos de esta parte de los Andes. Finalmente, exploraremos algunos aspectos de los antiguos cultos prehispánicos relacionados con las minas y los metales, los cuales se relacionan, igualmente, con los qollas. Los datos aquí presentados resultan de varios proyectos de investigación llevados a cabo, desde el año 2005 hasta el 2011, en regiones mineras de los departamentos de Potosí, Lípez y Pacajes y que estuvieron focalizados tanto en el estudio de la antigua minería y la metalurgia como en la cartografía religiosa asociada con las mismas.

\section{$*$ Las minas del altiplano sur de bolivia}

Nuestros estudios se centraron principalmente en los enclaves de Potosí y San Antonio de Lípez, ambos sitios localizados en el departamento de Potosí, y en menor medida en otros centros mineros y metalúrgicos, tales que Porco, Berenguela de Pacajes, Garci Mendoza y Oruro. En su conjunto, estos establecimientos productivos se localizan en un espacio que alterna extensas planicies de altura con formaciones montañosas de las cordilleras de los Asanaques, de los Frailes, de los Chichas y de Lípez. Desde el punto de vista geológico, la región, una de las más ricas en minerales metalíferos del planeta presenta dos importantes franjas metalíferas, la polimetálica (Berenguela, San Antonio) con depósitos epitermales de $\mathrm{Ag}-\mathrm{Au}-\mathrm{Pb}-\mathrm{Zn}-\mathrm{Cu}$, y la estañífera (Potosí, Porco) con

\footnotetext{
6 Utilizamos aquí el término "qolla" únicamente en un sentido locativo referido a los antiguos pobladores del Collao, sin adentrarnos en sus adscripciones étnicas y lingüísticas, las cuales conformaron un complejo escenario que supera las evidencias documentales y arqueológicas del presente trabajo. No obstante, a la luz de autores como Cerrón Palomino (2010) y Bouysse-Cassagne (2010), se trataría principalmente de poblaciones puquina hablantes, y en menor medida de aymaras y urus. Sumando confusión a este complejo escenario, es importante tener en cuenta, tal como lo señaló Bouysse-Cassagne (2010: 283-284), que la administración colonial no utilizó la categoría "puquina" como etnónimo, sino solamente las de aymaras y urus, incluyendo en estas, en función de su riqueza y área de actividad, a los puquina hablantes. Por esta razón, las referencias documentales sobre mitayos o mineros aymaras procedentes del Collao pueden referirse, más bien, a puquina hablantes. Por otra parte, escribimos qolla con "q" " "ll" a fin de evitar confusiones con el etnónimo actual "colla" del noroeste argentino.
} 


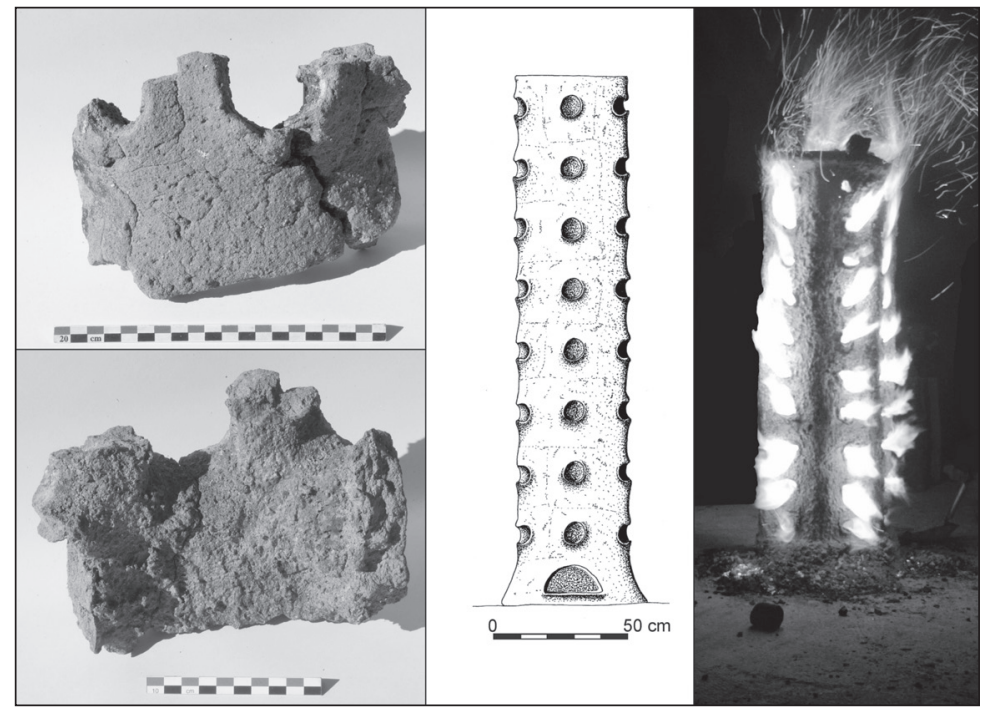

Figura 2. Fotografías (exterior e interior) de un fragmento huayrachina estandarizada de comienzos de la Colonia hallada en Potosí, reconstrucción gráfica y fotografía de un modelo experimental de la misma en funcionamiento.

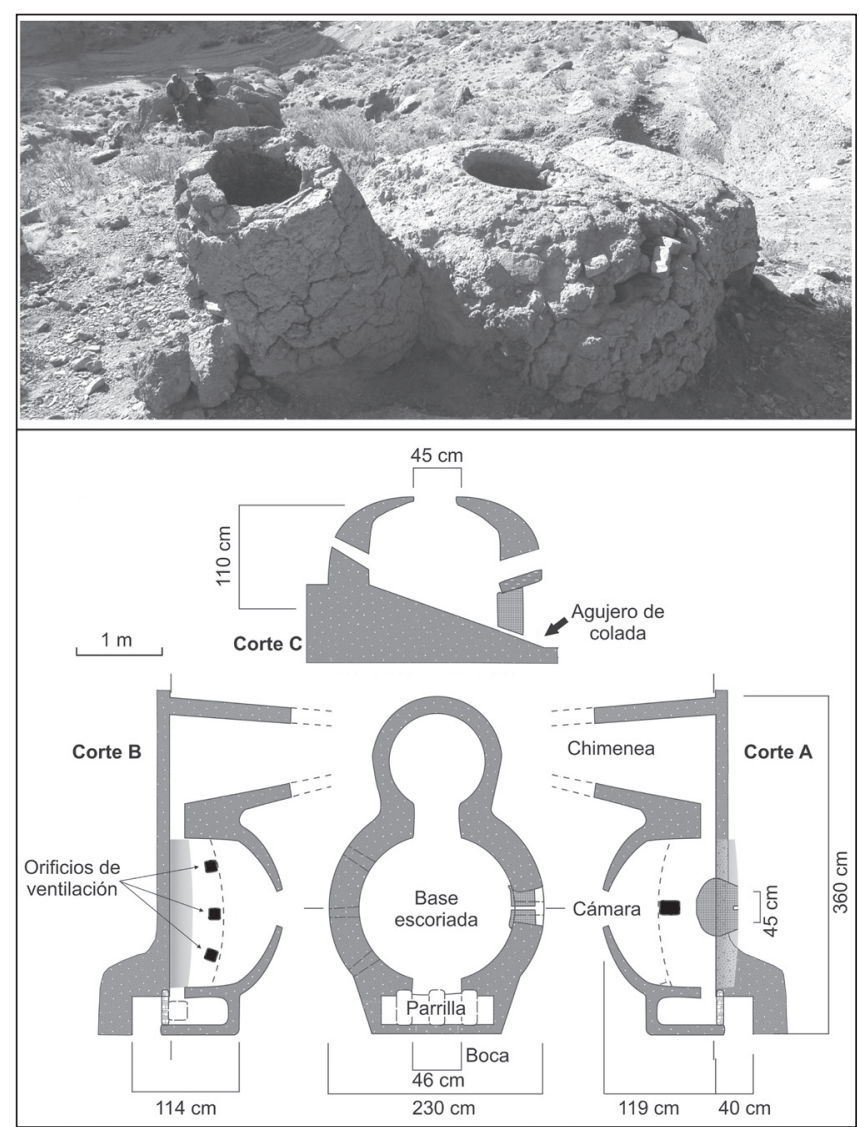

Figura 3. Fotografía y plano de un horno de reverbero colonial, probablemente del siglo XVI, registrado en Santa Isabel (Sud Lípez). 


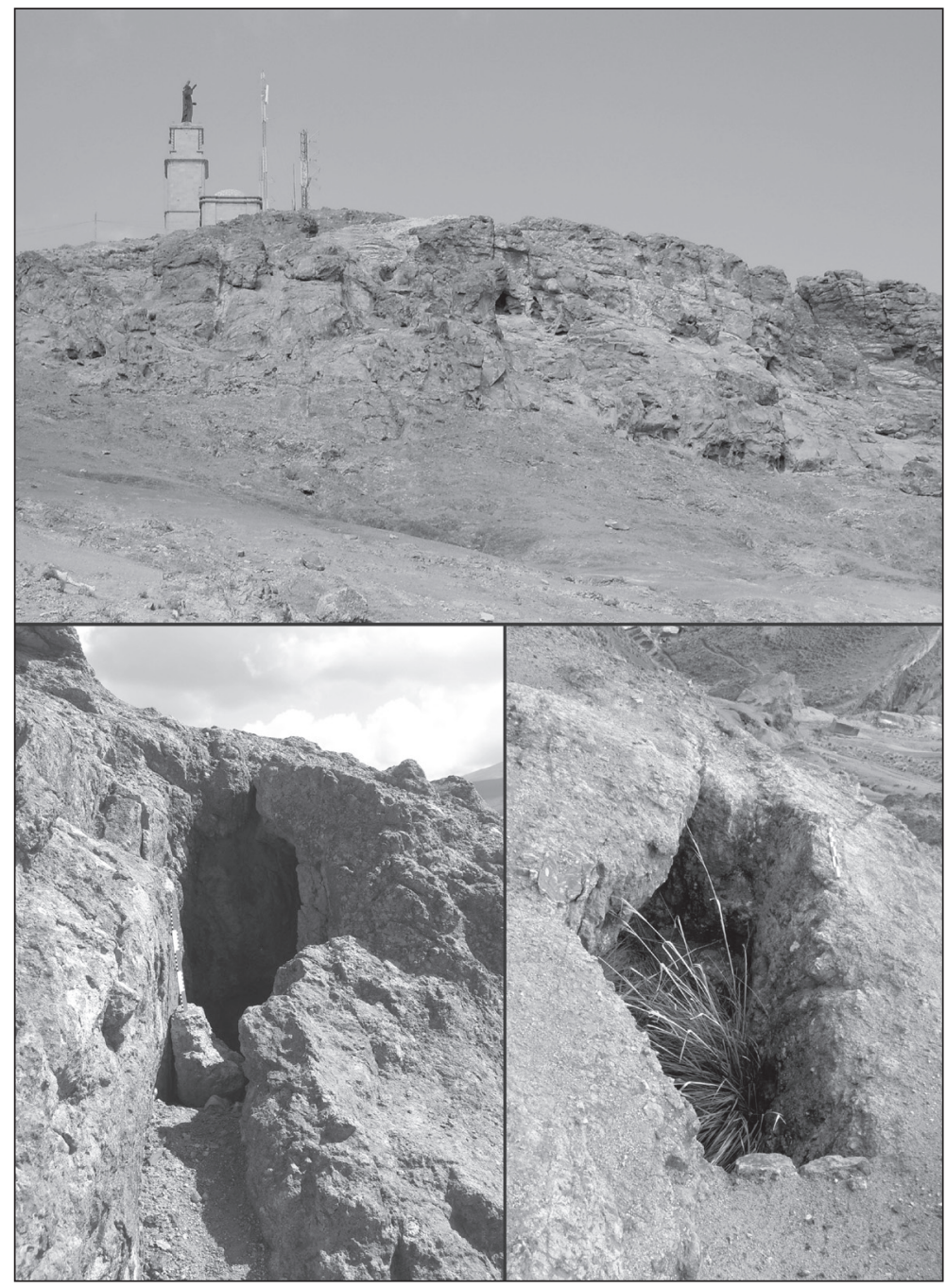

Figura 4. Cerro Huayna Potosí. Fotografías de antiguas explotaciones que siguieron vetas superficiales, muy probablemente de cronología de prehispánicas o de comienzos de la Colonia (siglos XV-XVI), y fotografía del sector donde ellas se ubican en el cerro.

importantes concentraciones de $\mathrm{Sn}-\mathrm{Ag}-\mathrm{Pb}-\mathrm{Zn}$ (ArceBurgoa y Goldfarb 2009).

Asociados principalmente con la producción de plata, cada uno de éstos enclaves mineros fue a su tiempo considerado como una inagotable fuente de riqueza. Aunque sólo en el caso del Cerro Rico de Potosí, el principal yacimiento de plata del planeta, la envergadura de la producción resultó a la altura de las expectativas generadas en su "descubrimiento". En función de la riqueza del yacimiento, estos enclaves se convirtieron en extensos centros productivos, pudiendo contener cada uno de ellos numerosas explotaciones mineras, las cuales se cuentan por miles en el caso de Potosí, e instalaciones metalúrgicas.

Un punto en común entre estos centros mineros se encuentra en su cronología prehispánica, la cual se pone en evidencia desde la materialidad tanto por la presencia de estilos cerámicos adscriptos principalmente al período Inka, como por la existencia de minas laboreadas con técnicas no europeas (Figura 4). No se trataría, sin embargo, de casos particulares. A lo menos en esta parte de los Andes, la mayoría de los principales yacimientos mi- 
neros explotados en los comienzos de la Colonia fueron trabajados con anterioridad a la llegada de los españoles. De hecho, uno de los primeros y principales objetivos perseguidos por los conquistadores europeos fue la obtención de informaciones precisas sobre las fuentes de metal trabajadas por los indígenas. De suerte que cada nueva noticia de "descubrimiento" de una mina, significaba, independientemente del sentido de la palabra, más bien la toma en posesión oficial por parte de los españoles de una mina ya conocida. En revancha, el hecho de que los españoles no hayan llevado adelante grandes campañas de prospección de minerales y cateo minero, habría sido una de las razones por las cuales resultaron tan efectivas las prácticas de ocultamiento de minas por parte de los indígenas. Así, la merma de la producción de Potosí a finales del siglo XVI impulsó a que los mineros españoles salieran en busca de nuevos "descubrimientos" de minas, sobre las cuales se tenía ya conocimiento de su existencia.7 Este fue el caso de las minas de Oruro, "descubiertas" oficialmente en el año de 1606, pero trabajadas anteriormente tanto por los inkas como por los españoles. ${ }^{8}$

Sobre los comienzos de la explotación colonial de estos centros, las fuentes brindan fechas precisas solo en los casos de Porco (1538) y Potosí (1545). Por su parte, las minas de Berenguela de Pacajes, ellas aparecen citadas en fuentes como la Relación de la Ciudad de la Plata de 1561 (Jiménez de la Espada 1885:352), por lo cual se dedu-

7 "...No puedo de dejar de decir el temor con que quedo de alguna baxa y quiebra por estar las minas de este cerro de potosí en gran hondura y sacanse los metales con mucha costa y no ser tan ricos como solia que es causa que los mineros y dueños de ingenios no les puedan beneficiar por no llegar por mucho a los gastos y así los mas estan pobres y empeniados y los obliga a buscar nuevos descubrimientos de minas que ay muchas en esta provincia..." 1606. Carta del Lic. Alonso Maldonado de Torres, Presidente de la Audiencia de Charcas. AGI Charcas 18 R.3 N.20 (fiv). Al respecto, ver también el Informe de Felipe Godoy de 1607 (en Pauwels, 1999).

8 "... Cincuenta leguas de esta villa en el asiento que llaman de oruro del corregimiento de Paria camino de la ciudad de los reyes se an descubierto unas minas de plata antiguas que en tiempos del inga se labravan. Yaunque ba muchos años que se tenia noticias de ellas y algunas pocas personas en diferentes tiempos trayan labores no se avia savido fuesen de la consideracion que ahora porque yendose continuando y abondando las minas se a echado de ber ser de mucha riqueza..." 1606. Carta del Lic. Alonso Maldonado de Torres, Presidente de la Audiencia de Charcas. AGI Charcas 18 R.3 N.20 (f2v). ce un comienzo de la explotación colonial alrededor de 1550. No resulta tan claro en el caso de San Antonio del Nuevo Mundo donde existe un vacío documental respecto a los primeros momentos de la explotación colonial que contrasta con el registro arqueológico, particularmente en lo que refiere a la presencia de estilos cerámicos prehispánicos y del período de Contacto. En efecto, las primeras referencias documentales sobre la mina de San Antonio aparecen recién a partir de la segunda mitad del siglo XVII y se multiplican desde finales de los años 1660 (Bakewell 1988). Sin embargo, es importante tener en cuenta aquí que en los Andes, como en muchas otras regiones mineras del planeta, se presenta con frecuencia un hiato cronológico entre los comienzos en la explotación de una determinada mina y la aparición de la misma en los registros documentales. Sin utilizar este nombre, otras referencias documentales sugieren que las minas de San Antonio fueron explotadas anteriormente. Por ejemplo, el Padre Álvaro Alonso Barba señala que las minas del Nuevo Mundo se descubrieron durante "su tiempo" en los Lípez, alrededor del año 1617 (Barba 1640: 48). Esta región del "Nuevo Mundo”, nombre dado según Lizarazu (AGI, Charcas, $20 \mathrm{R} 14$ N 161, $f_{1}$ ) “...no por su grandeza, sino por ser incognita y no haberla penetrado ninguno..." se corresponde geográficamente con el asiento y mina de San Antonio del Nuevo Mundo, el mismo que se encuentra situado a los pies de los cerros Lípez y Nuevo Mundo. Otra referencia aparece en un mapa anónimo del sur de Charcas elaborado en las primeras décadas del siglo XVII, donde figura una localidad asociada con un cerro llamado "los frayles" situado al sur de los Lípez, y a continuación de los cerros de Santa Isabel y Bonete de Cejas, la cual no podría tratarse de otra que la más tarde llamada San Antonio del Nuevo Mundo.' En conclusión, bien que el nombre de esta mina aparece tardíamente en los registros oficiales, el registro arqueológico y algunas referencias indirectas en las fuentes señalan que la misma habría sido trabajada por lo menos desde las últimas décadas del siglo XVI. De esta manera, entendemos que los cuatro establecimientos mineros donde centramos nuestros estudios fueron explotados por los españoles durante los primeros momentos de la Colonia, un aspecto importante en nuestro análisis.

9 El mapa se encuentra depositado en la Biblioteca Nacional de Francia (BNF, Ge DD 2983-4) y fue objeto de un pequeño artículo por parte de Thierry Saignes (1985a: 123-128). 


\section{* INkas y qollas en la minería y metalurgia} DE COMIENZOS DE LA COLONIA

Una de las recurrencias más significativas encontradas en los centros mineros de Potosí, Porco, San Antonio y Berenguela, a pesar de la distancia geográfica que los separa, se encuentra en el material cerámico representado en los mismos. Se trata básicamente de tres grandes grupos cerámicos, uno de tradición prehispánica, otro propio del período de Contacto (1532-1572) y otro Colonial. Como su nombre lo indica, el primer grupo se compone por estilos cerámicos de tradición indígena que perduraron durante las primeras décadas que siguieron la Conquista. Por su parte, el grupo cerámico del Período de Contacto se pone en manifiesto en vasijas en mayor o menor medida "europeizadas", pero que muestran una continuidad con los estilos prehispánicos. Finalmente, se adscriben al grupo colonial todas aquellas vasijas de formato europeo evidente, donde se destacan las superficies vidriadas y las lozas, las cuales se vuelven comunes en todos los establecimientos coloniales desde finales del siglo XVI. Nos concentraremos aquí en los dos primeros grupos.

El primer grupo se encuentra representado principalmente por los estilos Pacajes (o Saxamar en Chile) y Chilpe, el grupo estilístico denominado como Colla, o Altiplánico, la cerámica Inka (regional e imperial) y los estilos locales. Adscriptos a una cronología que se extiende desde los Desarrollos Regionales hasta los primeros momentos de la Colonia, ${ }^{10}$ los tres primeros fueron asociados con jurisdicciones territoriales yétnicas del altiplano hoy en día de habla aymara: Pacajes con Pakasa (Pärssinen y Siiriänen 1997), Chilpe con Karanqa (Michel 2011), y Colla con un vasto espacio en la porción sur del Collao (Qolla, Lupaqa y Pakasa). Éste último grupo comprende aquellos estilos identificados como Chucuito (Tschopik 1946; Hyslop 1976), Hatunqolla (Julien 1983), Altiplánico (Frye y de la Vega 2005) y Sillustani (Tschopik 1946). No obstante estas adscripciones culturales, las cuales pueden resultar algo forzadas, estos estilos fueron identificados en la totalidad del altiplano surandino, y más allá de éste, en el norte de Chile, con una serie de fechados preinkaicos (Schiappacasse et al. 1991; Muñoz y Chacama 1988,

\footnotetext{
${ }^{10}$ Véase Munizaga 1957; Daueslberg 1960; Niemeyer y Schiappacasse 1981; Schiappacasse et al. 1991; Muñoz y Chacama 1988; Pärssinen y Siiriänen 1997.
}

entre otros). Sin embargo, sería durante el período Inka que se incrementaría la difusión de estos grupos en todo el Qollasuyu, alcanzando regiones periféricas como el noroeste argentino. Así, salvo en el caso de la mina de Berenguela, situada en Pacajes, se trataría de estilos foráneos a las regiones donde se sitúan estos enclaves mineros. Finalmente, dependiendo de la localización de cada centro minero, se encuentran representados otros grupos cerámicos de tradiciones consideradas como locales, tales que Qaraqara-Yura en los casos de Potosí y Porco y Mallku en San Antonio.

Por su parte, en el segundo grupo cerámico se distinguen dos grupos estilísticos en razón de sus tratamientos decorativos. Uno de ellos, que identificamos como "Qolla Tardío I", se caracteriza por vasijas con superficies alisadas decoradas con diseños geométricos (líneas onduladas, círculos concéntricos y espirales) en color negro sobre la pasta natural, muy semejante al estilo Chilpe antes mencionado (Figura 5). El otro, que iden-

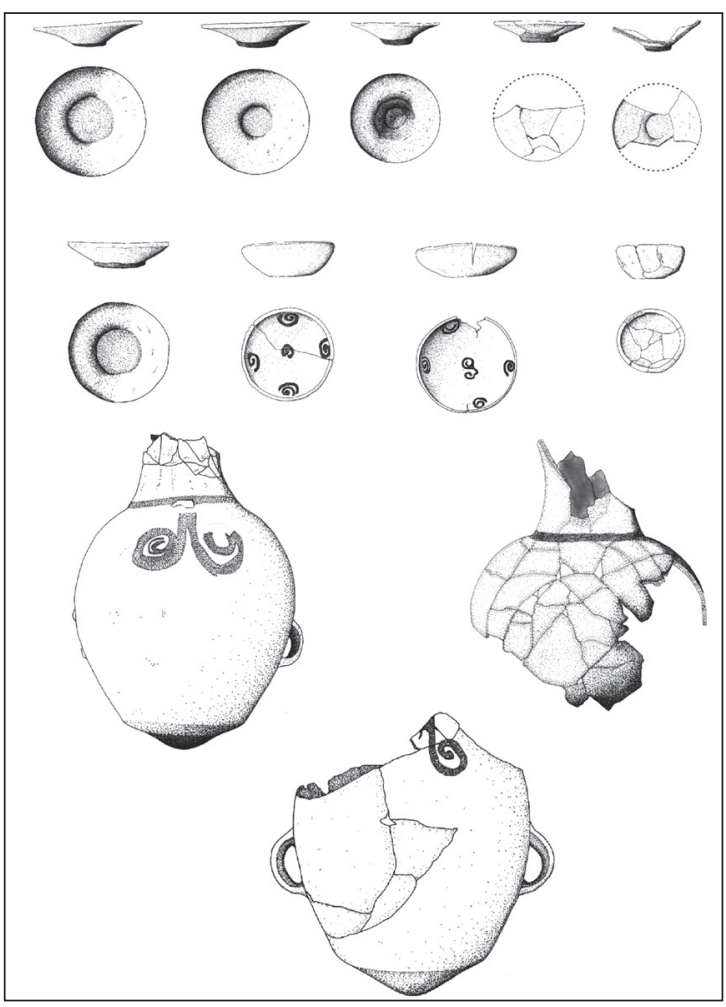

Figura 5. Cerámicas del grupo Qolla Tardío I registradas en el taller alfarero de Jesús Valle en Potosí. 
tificamos como "Qolla Tardío II", concierne principalmente platos y escudillas, generalmente con superficies pulidas, decoradas con los mismos diseños geométricos (conjuntos de líneas, líneas onduladas, espirales) y motivos zoomorfos realizados en negro, o en negro y blanco (puntos y líneas) (Figura 6). Ambos estilos resultaron contemporáneos.

Investigaciones desarrolladas años atrás en Potosí permitieron el registro y estudio de un taller alfarero asociado con estos dos grupos. El mismo se encuentra situado en el paraje denominado Jesús Valle, frente al río Hua- rampaya y el Cerro Chullpaloma, en el extremo norte de la Ciudad de Potosí. El sitio fue señalado en la obra de Arzáns Orzúa y Vela (1965 [1737]), por haberse librado allí una contienda en 1545 vinculada con la entrega del Cerro Rico, en la cual se enfrentaron "indios comarcanos", al mando de Chaqui Katari, y los españoles de Porco aliados en este evento con los inkas. Un $46 \%$ de los fragmentos cerámicos registrados en el taller de Jesús Valle corresponden a los grupos "Qolla Tardío I y II", mientras que un $32 \%$ se adscriben a los estilos Inka (regional e imperial) y un $22 \%$ a los otros grupos prehispánicos mencionados, principalmente Yura-Qaraqara

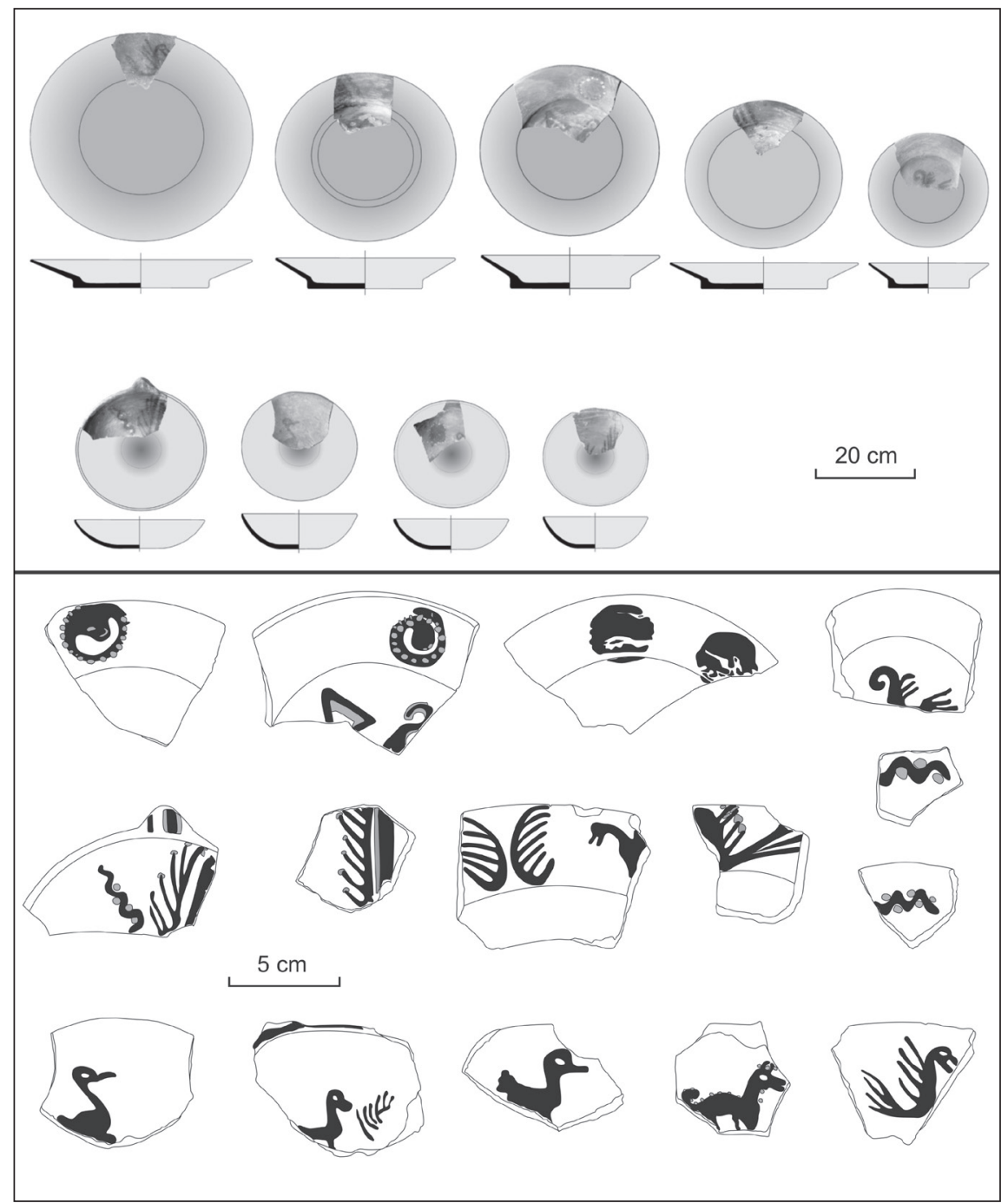

Figura 6. Fragmentos del grupo Qolla Tardío II registradas en la superficie del sitio Wayq'o Seco en San Antonio del Lípez. 
(11\%) (Figura 7). Las excavaciones realizadas permitieron tanto el hallazgo de un depósito primario de un conjunto de piezas cocidas, varias de ellas deformadas, los restos de una vasija cruda, panes de arcilla, concentraciones de pigmentos y alisadores cerámicos. Dos fechados AMS realizados sobre muestras de carbón de este contexto alfarero (sacA4828 y sacA4829) dieron como resultado 1480-1646 AP (95,4\%) y 1510-1600 (56\%), mostrando una curva que se muestra más homogénea en el siglo XVI. Asimismo, el hallazgo en la mayoría de sitios metalúrgicos con huayrachinas registrados en Potosí de fragmentos cerámicos análogos a los producidos en el taller de Jesús Valle fue interpretado como un testimonio, desde la materialidad, de la participación de los inkas a lo menos en una de las etapas en la producción de metales (Cruz y Absi 2008). Este habría sido igualmente el caso para los establecimientos minero-metalúrgicos de Porco, San Antonio de Lípez y Berenguela de Pacajes. En Porco y en Berenguela tales fragmentos fueron registrados en espacios asociados con antiguas actividades metalúrgicas. En San Antonio de Lípez, los mismos fueron hallados igualmente en un contexto asociado con la metalurgia en el sitio de Wayqo Seco, pero también en las minas de mesa de Plata, tanto al exterior alrededor de las bocaminas, como al interior en los socavones. Finalmente, es importante señalar que estos mismos grupos cerámicos fueron igualmente registrados en otras localidades con establecimientos mineros-metalúrgicos de comienzos de la Colonia, pero que no fueron objeto de estudio como las otras cuatro. Se trata de Garci Mendoza, al norte del Salar de Uyuni y Chaquí pocos kilómetros al este de Potosí, ambas con minas de plata prehispánicas, y Salinas de Yocalla, al norte de Potosí, donde se explotaron minas de sal desde comienzos de la Colonia.

Ahora bien, la recurrencia de estos estilos cerámicos nos condujo a cuestionarnos sobre la identidad de los grupos indígenas que participaron en la producción de plata durante las primeras décadas de la explotación colonial y sobre su relación con los inkas. En este planteo, las cerámicas Pacajes, Chilpe y Colla halladas en los establecimientos mineros referidos nos remiten inmediatamente a los grupos que poblaron el altiplano durante los períodos de Desarrollos Regionales e Inka, los cuales

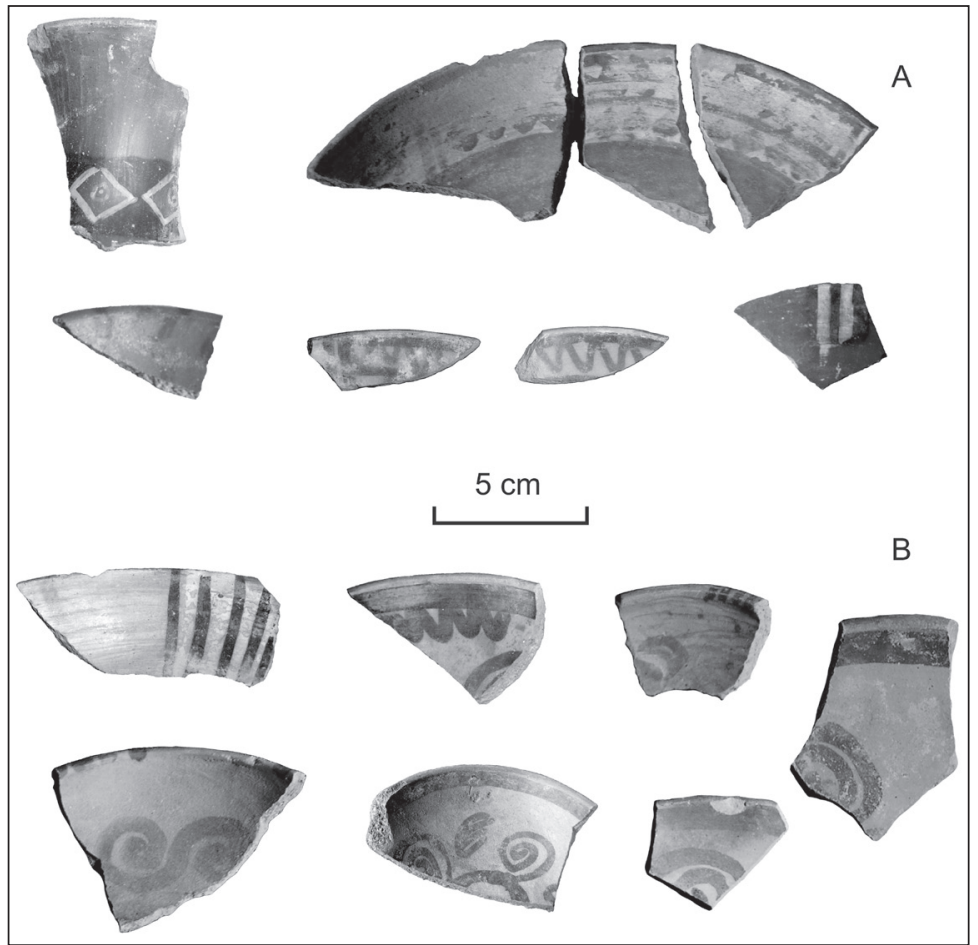

Figura 7. Fragmentos de cerámica Inka y Qolla Tardío I y II registradas en el taller alfarero de Jesús Valle en Potosí. 


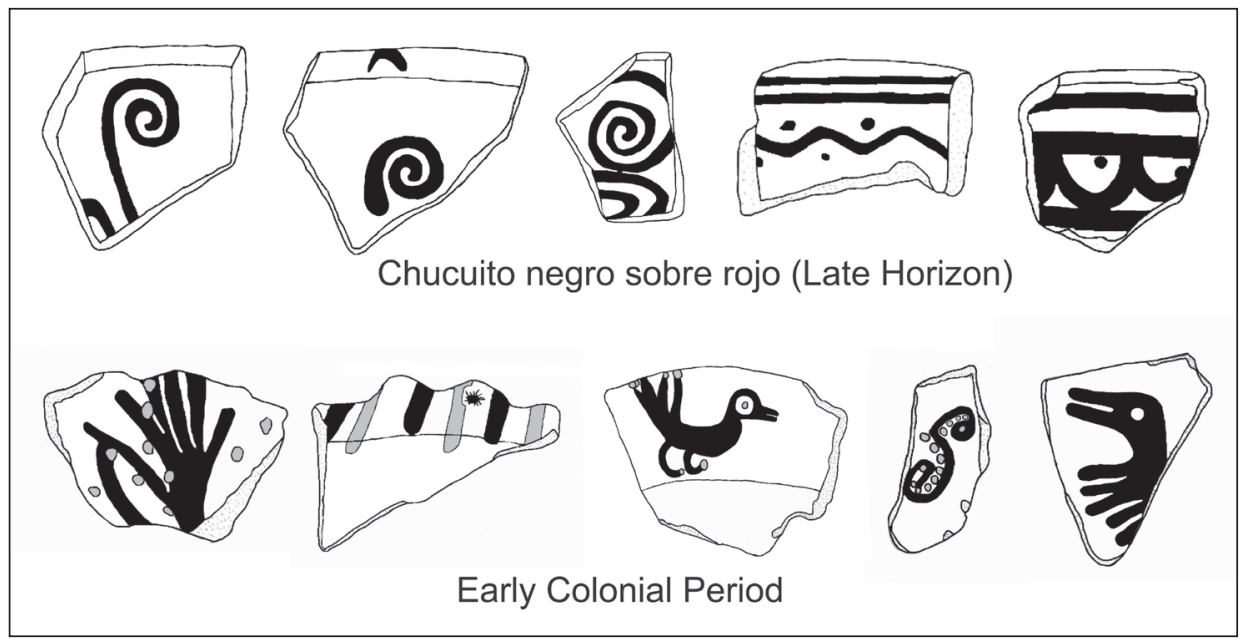

Figura 8. Fragmentos de cerámica Chucuito Negro sobre Rojo y Colonial Temprana procedentes de la península de Taraco (Bandy 2001 ; Bandy y Janusek 2005). Las mismas fueron redibujadas a partir de los dibujos originales publicados por los autores citados.

sabemos fueron desplazados por los inkas en calidad de mitmaqkuna prácticamente por todo el Qollasuyu. Pero lo que resulta verdaderamente relevante es la predominancia en estos sitios mineros de los grupos estilísticos que identificamos como "Qolla Tardío I y II", los cuales nos conducen al corazón geográfico del Collao: el área circunlacustre del Titicaca. En efecto, investigaciones desarrolladas en distintas localidades próximas a este lago confirman la presencia de estos dos grupos en tanto componente local adscripto a los primeros momentos de la Colonia. El mismo fue identificado como grupo Chocasu (con sus estilos Pleno, Bícromo y Glaseado) en el área de Juli-Desaguadero en la ribera peruana del lago (Stanish et al. 1997: 31ss.). En la península de Taraco, en el margen sur del Titicaca, el mismo fue denominado como Colonial temprano, comprobándose su continuidad con los estilos prehispánicos Chucuito negro sobre rojo y $\mathrm{Pa}$ cajes (Bandy 2001; Bandy y Janusek 2005) (Figura 8). Finalmente, fragmentos de este mismo grupo fueron registrados en el área de Hatunqolla, al norte del Titicaca, adscribiéndolos cronológicamente a la fase 4 (período de Contacto) en la secuencia establecida para esta región por Julien (2004). En este sentido, la presencia de estos estilos cerámicos en contextos mineros y metalúrgicos de comienzos de la Colonia atestigua, desde la materialidad, la participación de yanaconas oriundos de estas regiones en la producción colonial de metales. Como veremos a continuación, a lo menos hasta 1572, la misma se habría desarrollado bajo tutela de los inkas, en concordancia con lo observado en Potosí desde la arqueología (Cruz y Absi 2008), en continuidad con las antiguas prácticas de traslado de mitmaqkunas.

\section{Los yanaconas qollas en las minas de Charcas}

Una de las primeras referencias sobre la procedencia del Collao de los mineros que trabajaron en las minas de Potosí nos la brinda Espinoza Soriano (1972: 1). Se trata de un documento de Polo de Ondegardo de $1550^{11}$ donde se refiere al trabajo de mitimaes originarios de Copacaguana (Copacabana), los cuales, según Espinoza Soriano no serían otros que varios de los 500 tributarios que anteriormente laborearon las minas de oro de $\mathrm{Ca}$ rabaya al servicio de sus encomenderos según lo señala un documento anónimo de $1548 .{ }^{12}$ Otro documento, redactado en Potosí en $1571,{ }^{13}$ pocos años antes de que

${ }^{11}$ Comisión dada al Licenciado Polo, Corregidor de la villa de la Plata, para entender en la libertad que tenían para irse a sus tierras los indios de la mina de Potosí (AGI, Justicia, 667).

${ }^{12}$ Anónimo, 1548. Memoria exacta i completa de los repartimientos de esta ciudad del Cuzco asi vacos como los que tienen dueños. En Documentos para la historia del Perú. Alardes y derramas. Por Rafael Loredo del Instituto Histórico del Perú. GIL S.A. Impresores. Lima.

13 Orden que se dio en Potosí para que los indios no hiciesen fundiciones de plata y nombramientos de alcaldes que se hicieron en varias doctrinas. Gerónimo Luis de Cabrera, Potosí 15 de marzo 


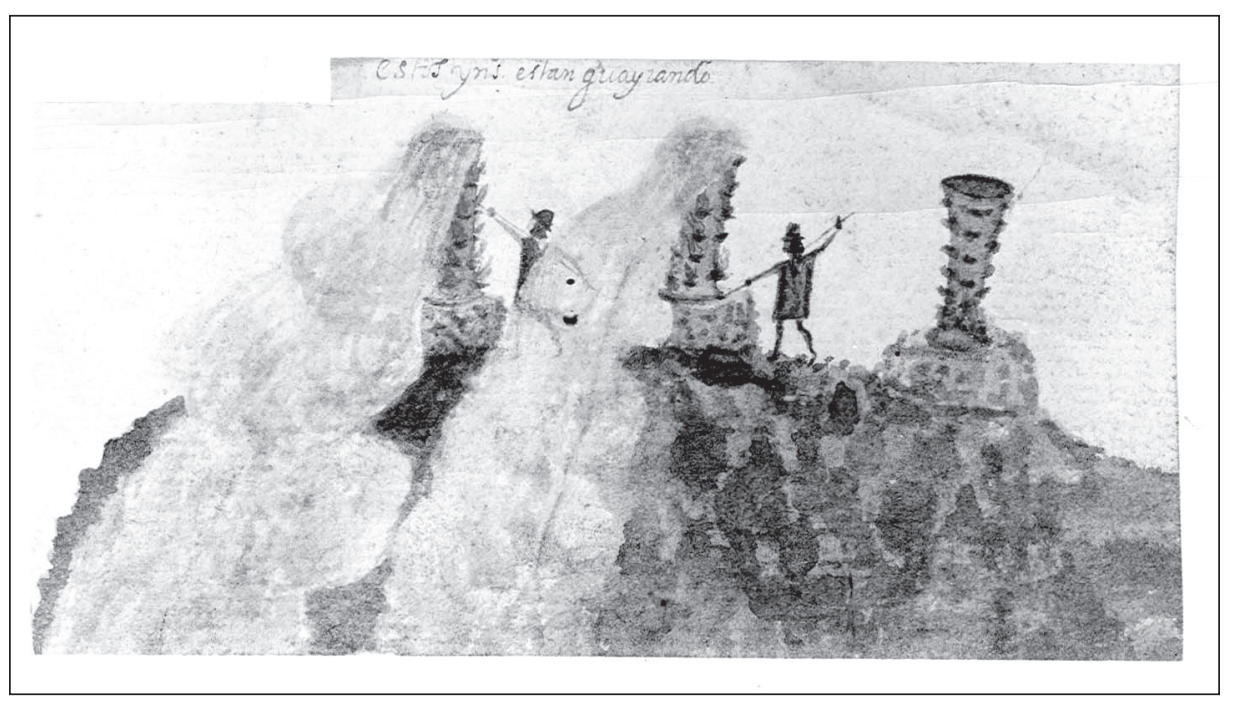

Figura 9. "Éstos yndios están guayrando". Dibujo anónimo del siglo XVI. Atlas of the Sea Charts, The Hispanic Society of América.

se ejecutaran las reformas dictadas por el Virrey Toledo, en el cual se ordena que los indígenas yanaconas no hiciesen fundiciones de plata por su cuenta, nos refiere un listado de los diferentes grupos étnicos convocados en las labores del metal. Es relevante que, por entonces a pocos meses del arribo del sistema de amalgamación, la metalurgia de Potosí continuaba siendo operada esencialmente en dos tipos de hornos, las huayrachinas para la extracción del plomo argentífero, y los hornos de reverbero, utilizado tanto para la extracción como para la refinación y obtención de plata metálica (Figura 9). Los yanaconas especializados en el manejo de estos tipos de hornos, procedentes de varias regiones andinas, fueron organizados y supeditados a siete doctrinas ${ }^{14}$ que contaban con Parroquias de Indios en la Villa Imperial. Cada una de estas doctrinas se encontraba bajo el control de un indígena principal o un curaca que oficiaba como Alcalde Mayor. Según el documento, los grupos de yanaconas huayradores eran originarios de 77 localidades, la gran mayoría de ellas ubicadas en el espacio alto-andino, y una mínima parte procedente de los valles. Del total de estas localidades, un 64\% (49) formaban parte de lo que se conocía como el Collao, estando representadas las

\footnotetext{
de 1571. BN/Ms 3040 fs. 167r-169v.

${ }^{14}$ Nuestra Señora de la Concepción, San Pablo, San Pedro, Santiago, Santa Bárbara, Nuestra Señora de la Asunción de los Carangas y San Agustín de los Lupacas.
}

provincias de Pacajes con 12 localidades, Lupaqas con 9 , Hatuncolla con 15 y Canas y Canchis con 13. El resto de los yanaconas provinieron de diferentes regiones: Sora (6), Carangas (3), Quillacas-Asanaques-Huruquillas (3), Qaraqara (6), Lípez (1), Chichas (1), Huancavelica (1), Chumbivillcas (1) y Arequipa (4) (Figura 10). Aparte de estas cifras, que muestran de manera muy clara la preponderancia de yanaconas fundidores procedentes del Collao en la metalurgia temprana de Potosí, resalta el número de Alcaldes que fueron miembros de la élite inka. Es importante tener en cuenta que por entonces, Potosí se había constituido en un centro para la élite indígena, un "taypi", o incluso un "Cuzco" surandino, retomando la idea de Bouysse Cassagne (1987: 124), albergando entre otras figuras notables a Carlos Inca, hijo del mismo Inka Paullu. Asimismo, Capoche (1959 [1585]) nos revela que la mayoría de los indígenas que poseían minas en el cerro de Potosí -ciertamente un número reducido en comparación con los españoles-, eran igualmente originarios de pueblos del Collao..$^{15}$ Aun durante los años que siguieron a la implantación del proceso de amalga-

\footnotetext{
${ }^{15}$ Entre otros indígenas que no cuentan con referencias de origen: Alonso Cavana (colla), Domingo Quinta (Yunguyo, lupaqa), Antonio (Quispicancha, cuzqueño), Francisco Chuquisana (Sicuana, cana), Bartolomé Guamani (cana), Lorenzo Liqui (Puno), Juan Consa (canchi), Diego Guanca (Pomata) y Antón Lusco (canchi),
} 


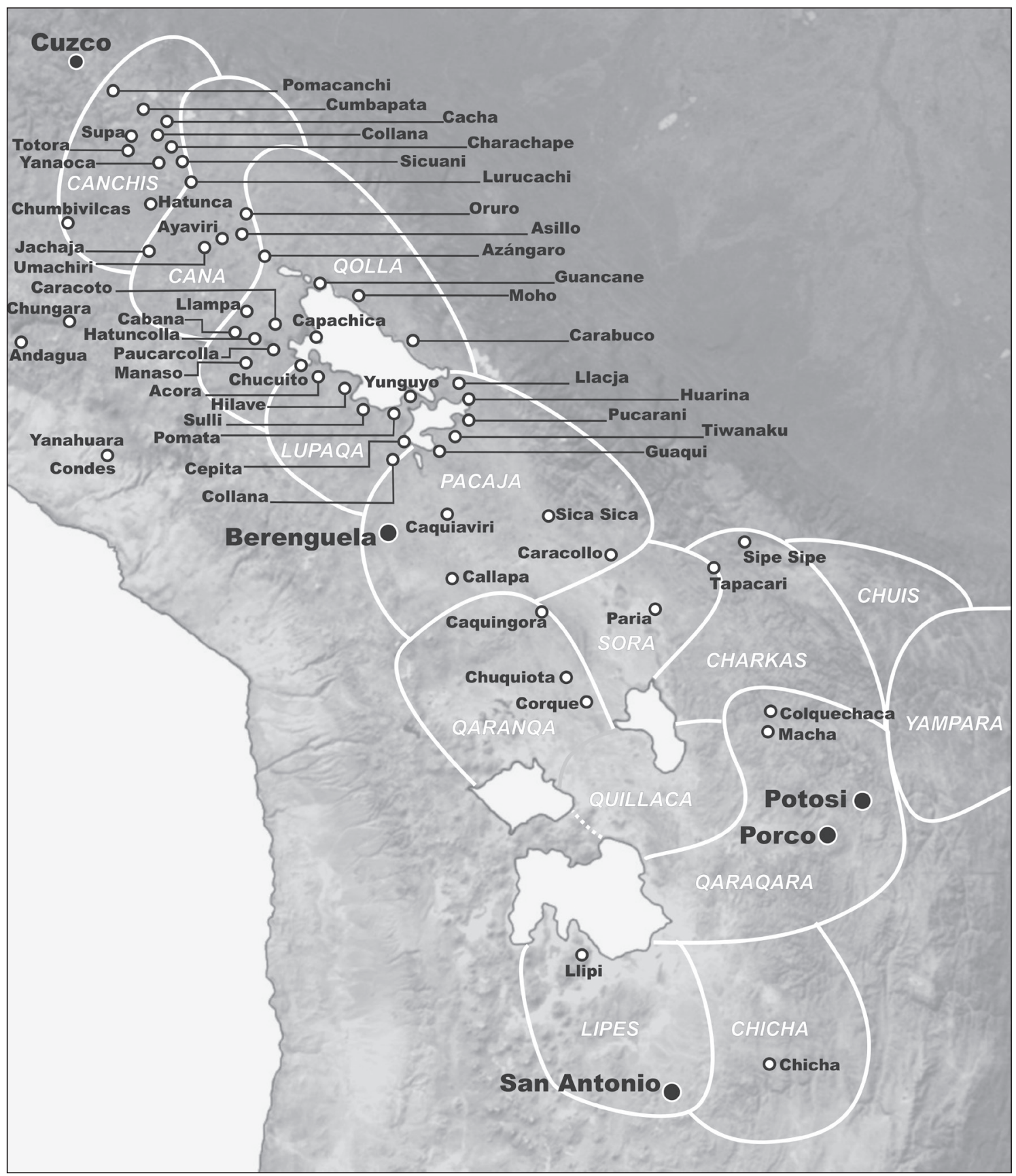

Figura 10. Mapa con localización de las localidades de procedencia de los yanaconas trabajando en Potosí en 1571 según informaciones del documento tratado (BN/Ms 3040 fs. 167r-169v).

mación y del sistema de mita los yanaconas huayradores qollas continuaron teniendo en sus manos los procesos de producción de plata. Esto lo vemos claramente en un padrón de 1575, tratado por Escobari (2011), don- de se señala que el $80 \%$ de los yanaconas establecidos en Potosí, unas 536 personas, oficiaban todavía como "huayradores" -muy probablemente reactualizados en el manejo del azogue-, observándose un mayor número de 
fundidores procedentes del norte del Titicaca y el Cuzco (Figura 11). Sin embargo, la baja en la ley del mineral y el remplazo de la tecnología de la huayra por el sistema de amalgamación con mercurio reducirían paulatinamente la participación de los qollas.

De hecho, esta merma en la mano de obra necesaria para el trabajo de las minas e ingenios, en una época en que según Capoche (1959 [1585]: 135) "...el asiento de Potosí estaba casi despoblado, y muy arruinados los edificios y los vecinos con poca plata..." habría conducido a que intensificaran el tributo en fuerza de trabajo indígena establecido por Toledo. En ello se dictaminó explícitamente que lo principal de esta mano de obra forzada continuara siendo provista por las provincias del Collao, los cuales llegaron a constituir el 67\% de los 13.340 mitayos destinados a las minas e ingenios de Potosí señalados por Capoche. ${ }^{16}$ De manera colateral, la alta valoración que tuvieron los pobladores del Collao en la producción del metal de Potosí dentro del sistema de la mita, condujo en pocos años a un despoblamiento significativo de las comunidades de origen que desembocaron en notorios cambios en el modo de establecimiento en la región (Sánchez Albornoz 1994; Saignes 1985b), situaciones puestas en evidencia igualmente desde la arqueología en el área de Tiwanaku por Albarracín Jordán (1996) y en la península de Taraco por Bandy y Janusek (2005). Tal fue el impacto de las migraciones mineras en la economía agrícola de la región circunlacustre que se dispuso, incluso, que los urus que cohabitaban con los puquinas y aymaras en las riberas del Titicaca -y que no eran considerados aptos para la minas-, prestaran servicio en las chacras y menesteres de sus vecinos durante los años que duraba su prestación de mita. ${ }^{17}$

\footnotetext{
16 "...En el memorial que se dio a vuestra magestad toca lo que esta audiencia proueyo cerca de que los indios de aquella prouincia es obligada a dar para que uengan a trabajar a la villa de potosi en los beneficios de las minas y metales sean aimaraes..." / “... los aymaraes es gente politica y acta para ocuparlos en cualquier labor y ministerio y que sauen trabajar y hacer lo que conuiene y es necesario en las minas y beneficios de metales de Potosi..." Carta a S.M. de los Licenciados Cepeda Lopidana, 31 de diciembre de 1586. Levillier (1922: 278)

17 “...Por la tassa primera heran obligados a dar los dichos yndios de la dicha Provincia de chucuyto dos mill y ducientos yndios en cada año para el beneficio de las minas y metales de la Villa de Potossi los un mill ochocientos aymaraes y los cuatrocientos huros y porque los huros de ordinario se huyen y no se podian servir de ellos la Real audiencia de la ciudad de la Plata mando que todos fuesen aymaraes y que los huros sirviessen en la provincia para trajines y mitayos y reservas destas cargas a los aymares..." Carta a
}

Lamentablemente las informaciones sobre el origen de yanaconas mineros o huayradores en otros centros mineros son sumamente escasas y pobres en comparación con el padrón de Potosí. Aun así, los pocos datos hallados continúan resaltando la participación de grupos procedentes del Collao. Por ejemplo, en el informe de Felipe de Godoy sobre la mina de Oruro, redactado poco tiempo después de la fundación de la Villa Felipe de Austria en 1602 , se señala que el trabajo de las minas estuvo a cargo de indígenas comarcanos procedentes de Pacases, Collas de Omasuyo, Chucuito y de Paria. ${ }^{18}$ Otras fuentes dan cuenta de que al menos algo de la participación de especialistas qollas en la producción de metales en esta área de los Andes remontaría a tiempos del Inka. Por ejemplo, según el manifiesto de la Coya Cusihuarcay, Sayri Tupac, hijo de Manqo Inka Yupanki, quien gobernó desde el refugio de Vilcabamba hasta 1560, tenía a su servicio 4500 qollas para el trabajo de las minas del Qollasuyu. Una de esas minas fue la de Carabaya, para cuya explotación el Inka relocalizó un importante grupo de mitmaqkuna qollas procedentes de las localidades de Asillo, Azángaro y Ñuñoa (Berthelot 1978: 952-953; Bouysse-Cassagne 2005: 448). En este sentido, es muy probable que los 500 mitimaes de Copacabana que trabajaron en 1548 en las minas de Carabaya para beneficio de los encomenderos (Espinoza Soriano 1972), lo hicieran antes para el Inka en tanto que mitmaqkuna. Este podría ser también el caso de los mitmaqkuna Pacajes y Lupacas establecidos en los alrededores de Potosí, y de un porcentaje de los 4000 aymaras instalados en la tierra de los Lípez, los cuales fueron vinculados con el laboreo de las minas -aunque de manera algo ambigua-, por el factor Lozano Machuca (1992 [1581]). En cuanto a la mina de Porco, sin duda uno de los principales yacimientos de plata explotados por los inkas en la región, Saignes (1981:157ss.) señala la presencia de mitmaqkuna lupacas destinados al laboreo de las antiguas minas del

\footnotetext{
S. M. del Licenciado Cepeda, 20 de febrero de 1585. Audiencia de Charcas. Correspondencias de Presidentes y Oidores. 1922. Documentos del Archivos de Indias, P. Levillier dir. T.II Biblioteca del Congreso Argentino. Imprenta Juan Pueyo, pp. 188.

18 “... Los yndios que trabajan en las dichas minas son los que están //f.nuv// en la población y ranchería de la dicha villa que se an juntado de todas las provincias comarcanas: Pacases, Collas de Omasuyo, Chucuito y de la misma provincia de Paria donde está la dicha villa y asiento de minas...". Description de la Villa de Sanct Philippe de Austria, Asiento y Minas de Oruro (Pauwels 1999: 133).
} 


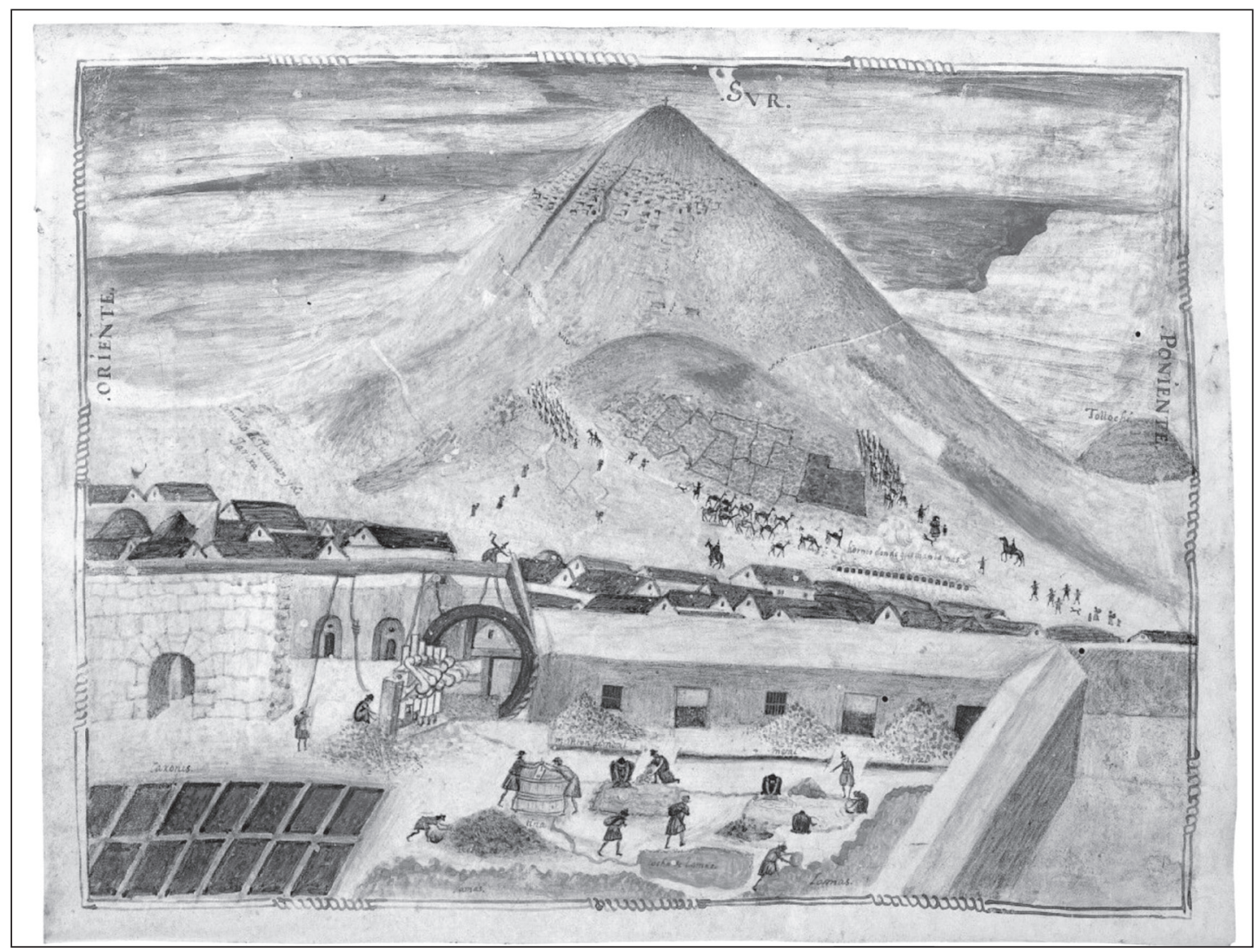

Figura 11. Dibujo de un ingenio de Potosí en 1585. The Silver Mines of Potosí, acuarela sobre pergamino, anónimo de 1585. The Hispanic Society of America.

cerro. Y de la misma manera que en Carabaya, es muy probable que algunos de los yanaconas qollas que desde 1538 trabajaron en Porco para los españoles y más tarde en Potosí, como es el caso de Diego Guallpa, hayan cumplido anteriormente estas funciones para el Inka en tanto que mitmaqkuna. Es importante tener en cuenta aquí que, según el Memorial de Charcas (Espinoza Soriano 1969), las minas de Porco fueron entregadas a los españoles en 1538 , en un claro afán por ocultar el cerro de Potosí, por Kuysara y Muruq'u, señores de la federación Qaraqara-Charkas y por el Mallku de los Killaqas-Asanaques, Warachi. Tal como lo sugieren Platt et al. (2006: 125-132), estos señores aymaras de Charcas pudieron haber compartido las riquezas minerales del cerro de Porco, aspecto que resultaría en gran medida coherente con el hecho de que aparte de un yacimiento minero se trataba de un importante centro religioso regional. En este sentido, y aunque desde el punto de vista territorial estos documentos conciernen a grupos señalados como aymaras de Charcas (Qaraqara-Charkas, Killaqas), es de relevancia los lazos de linaje que ligaban a los Warachi señores de los Killaqas-Asanaques con los propios Warachi de Pacajes del Collao, quienes se proclamaban como los antiguos gobernantes -con anterioridad a los inkas-, de un amplio territorio que abarcaba desde el Titicaca hasta Potosí. ${ }^{19}$ Es decir, es posible que la participación de los especialistas oriundos del Collao en las labores de las minas de Porco fuera anterior a la llegada de los inkas.

19 “...dominó antes de los Ingas Reyes naturales de este Reyno desde el Desaguadero hasta los contornos de Potosí y Chuquisaca...” “... y tenía sus palacios en hatunquillaga y en asanaqui en la provincia de Paria..." Memorial de los méritos y títulos de la familia de Don Joseph Fernández Guarachi, descendiente de Qhapaq Yupanqui, de Wirakucha Inga, Mayta Qhapaq y demás Monarcas del Cuzco. BCUMSA, Doc. 191, f. 12v. Tomado de Choque Canqui (2003: 51). 
Asimismo, es importante tener en cuenta que, aparte de su intervención directa en la extracción y procesamiento de minerales metalíferos, los qollas intervinieron en otro eje crítico de la producción minera: la ganadería. En efecto, durante estos primeros años fue gracias al empleo de las caravanas de llamas que se transportaron, muchas veces sobre espacios dificultosos cuando no inaccesibles, tanto los insumos para explotar las minas, como el mineral extraído de ellas. De la misma manera, fueron en estas caravanas que se acarrearon los combustibles requeridos para el funcionamiento de los hornos, incluso desde regiones muy distantes, así como los víveres indispensables para los trabajadores. Finalmente, ellas tuvieron un rol principal en la circulación de los metales entre los diferentes centros de producción y los puertos de embarque a España, Lima o Arica, cuyos recorridos atravesaban los territorios del Collao. Solamente en las labores de las minas de Potosí, a comienzos del siglo XVII, se empleaban unas 12.000 llamas de carga, repartidas en mitas de 4000 animales cada una, mientras que otros 100.000 "carneros de la tierra", principalmente procedentes del Collao y Pacajes, eran destinados anualmente para el "mantenimiento de los indios" (Ocaña 1969 [1605]).

\section{* Los cultos mineros y la divinidad del Rayo}

En los Andes prehispánicos, la generación de los minerales metalíferos se hallaba directamente vinculada con los cultos a las montañas, ellas mismas consideradas como manifestaciones de divinidades, cuando no divinidades a parte entera, generalmente identificadas bajo el denominativo genérico de wak'a. Más allá de sus condiciones intrínsecas, la valoración simbólica de los metales se hallaba pues en gran medida relacionada con las características de las montañas-wak'a que proveyeron los minerales que los formaron. Tal vínculo no pasó por alto ante los ojos de la Iglesia, quien alertaba a sus oficiantes sobre la devoción a las montañas que manifestaban los mineros indígenas: “... También usan los que van a las minas de Plata, o de Azogue, o de otros metales adorar los cerros y minas pidiendo les dé de su metal, y para esto velan de noche bebiendo y baylando..." (Alcobaza 1603: 64). Por esta misma razón, el extirpador Avendaño sentenciaba años más tarde: “... Quando vais a las minas, o a pleitos, consultais a los hechizeros, $y$ velais de noche, beuiendo y baylando. Quando llegais allá, hazeis otro tanto, para que os suceda bien vuestro negocio, o el pleito, o el metal que buscais. Para eso adorais los cerros, y las minas..." (Avendaño 1648: 34). Desde lo figurativo, la devoción dada a los wak'a mineros fue plasmada a lo largo del tiempo en conocidas pinturas de la montaña de Potosí, como las "Virgen del Cerro" (Anónimos del siglo XVII), y más tarde en el "Cerro Rico y la Villa de Potosí” de Gaspar Miguel de Berrío (1758). Los cultos mineros se extendieron incluso a los sitios de fundición, muchos de los cuales se encontraban localizados sobre las faldas de los mismos cerros-wak'as, donde se veneraban a los hornos metalúrgicos y a los metales producidos en ellos.

“... Lo mismo solian hazer en las minas que llaman copa que adoraban y reberençiavan a los metales que llaman mama y a las piedras de los metales que llaman corpas. Adoravanlas vezandolas, $y$ haciendo diferentes ceremonias y a las pepitas de oro y oro en polvo y la plata, y las guayras donde se funde la plata..." Murúa (2004 [1590]: Ch 4.9: 101). La transcripción es nuestra.

Tal como fue ampliamente tratado por Bouysse-Cassagne (2004, 2005, 2008), muchos de los cultos mineros y aquellos asociados con la producción de metales estuvieron vinculados con la divinidad del Sol. De hecho, varias de las principales minas prehispánicas, como las de Carabaya, Porco y Oruro, tuvieron vetas destinadas al Sol (Berthelot 1978; Bouysse-Cassagne 2004, 2005 , 2008; Pauwells 1999). El mismo cerro de Potosí, llamado antiguamente en lengua puquina Qhapaq Yque (Señor Rico), habría sido consagrado al Sol por los inkas -y posiblemente lo encarnaba-, en razón de sus riquezas minerales (Bouysse-Cassagne 2004: 59-97). En este sentido, cobra relevancia la propuesta de Platt y Quisbert (2008) sobre la participación de Baltazar Challco Yupanqui, hijo de Apo Challco Yupanqui, Gobernador del Qollasuyu y Ministro del Sol en Copacabana en el descubrimiento y entrega del cerro de Potosí a los españoles.

Sin embargo, como veremos a continuación, otras relaciones vinculaban igualmente la producción de metales en las regiones tratadas con la divinidad andina del Rayo. Por ejemplo, por un documento de 1625 sabemos que el wak'a- mina de Chaquí, situada el cerro llamado Poder de Dios, estaba representada por tres piedras que marcaban su entrada, de las cuales una se encontraba asociada con el Sol y otra con el Rayo (Platt et al. 2006: 146-156). Estas relaciones son significativas ya que nos remiten nuevamente sobre el mundo qolla. La imagen de la divinidad del 
Rayo era la de un pastor-guerrero celestial blandiendo una waraka y una porra. ${ }^{20}$ Bajo su dominio se encontraban regulados los fenómenos meteorológicos, como las lluvias y el granizo, de allí su importancia capital en las sociedades altoandinas. El proyectil lanzado por Illapa -por utilizar uno de sus múltiples nombres indígenas-, una esfera de oro nombrada por Murúa (2004 [1590]: 255) como Chuqui-rumin -piedra de oro o resplandeciente-, actuaba en su impacto como un agente fecundador en la generación de las vetas minerales (Bouysse-Cassagne y Bouysse 2006: 2; Ziólkowski 1984). Cronistas como Guaman Poma (1989 [1615]: 265) señalaron que Illapa era por otro nombre llamado Curi Caccha, el cual puede ser traducido como "resplandor de oro", en una clara alusión al proyectil metálico por él lanzado. Por su parte, Betanzos (1987[1551]: 221) nos dice que Caccha "es el nombre del ídolo de las batallas". Este nombre, que en lengua puquina designaba más bien el "fuego del cielo", se encontraba asociado con los volcanes, de allí también su vínculo con la generación de los metales y con la figura de Tunupa (Bouysse-Cassagne y Bouysse 2006), una de las principales divinidades del altiplano qolla, maestro del fuego celestial y del agua terrestre. De hecho, Tunupa es considerado por los aymaras contemporáneos como el Dios del Rayo y del Trueno, confundiendo su figura con la de Illapa (Wachtel 1989: 854). Tal fue la devoción dada por los pobladores del Collao a esta divinidad que los mismos fueron considerados como "hijos" y "descendientes" del Rayo (p. e. Avendaño 1648: 111ss; Hernández Príncipe 1923 [1621]).

Por otro lado, la figura del proyectil arrojado por el Rayo nos remite directamente a las "yllas" o "mamas" de las minas, las cuales, tanto en tiempos coloniales como en el presente, fueron celebradas por su capacidad de engendrar los minerales (Murúa 1613; Bouysse Cassagne 2005: 447; Absi 2005: 84) (Figura 12). Se trata en ambos casos

\footnotetext{
20 “... Abíaseme olbidado dezir que, después de la huaca del Biracochay el sol, la tercera en lugary estimación que tenían, eva la del trueno, a quien llamaban chuquiylla, catuylla y yntiyllapa, y finjían que es vn hombre que en el çielo estaua con una honda y porra en la mano, y que estaua en su boluntad el tronar, llober, granizary todo lo demás que pertenese a la rejión del ayre $y$, en jeneral, reberenciauan [a] ésta en todo el reyno, y le sacrificauan niños de la [misma] manera que al soly si, quando tronaua acaso acontecía parir alguna muger en el campo, decían que la criatura que nacía era hijo del trueno, y ansí se auía de dedicar a su seruicio, y aun oy día lo afirman, y ay mucho número de hechizeros que llaman hijos del trueno...". Martín de Murúa (1961[1613]: 109, párrafo 34)
}

de los primeros bloques de mineral extraídos en la apertura de una nueva mina o aquellos bloques que presentan una forma extraordinaria. Tal como nos cuenta Cristóbal de Albornoz: "... Han escogido las más hermosas piedras de los metales y los han guardado y guardan y los mochan llamándolas madres de las tales minas. Y, primero que los vayan a labrar, el día que han de travajar, mochan y beven a la tal piedra llamándola mama de lo que travajan..." (Albornoz [1582] en Duviols 1967: 18). En un universo minero regido por las mismas lógicas que la agricultura y la ganadería, las yllas actuaban como arquetipo fecundador, emanando las fuerzas y principios propios del Rayo. Hoy en día, los yatiris aymaras, o los jamp'iris quechuas, reciben sus capacidades extra-humanas tras haber sido tocados por el rayo. Y entre las principales herramientas rituales utilizadas por estos especialistas se encuentran las "yllas" o "balas", nombres que en este contexto designan aquellas piedras esféricas y antiguos proyectiles coloniales vinculados con Santiago, santo que encarnó a la antigua divinidad del Rayo, y que en función de tal, son portadoras de poderes mágicos.

Las fuentes nos señalan que, siguiendo un orden jerárquico, el Sol, Viracocha y el Rayo fueron las principales divinidades dentro de la religión inkaica. Sin embargo, la posición subalterna del Rayo frente al Sol, o a Viracocha, puede matizarse si se considera tanto su preeminencia en las clases o sectores populares, tal como lo señalaron respectivamente Demarest (1981) y Millones (1982: 242243), como en el fuerte arraigo de su culto entre la élite inkaica. El propio Vila Oma, quien se supone fue hijo de Wayna Qhapaq, capitán y sumo sacerdote del Sol al momento de la conquista española, y quien habría labrado las minas que poseía en Porco, era llamado "hijo del trueno" (p. e. Cobo 1964 [1653]). Más aun, Pachacuti Inka, quien organizara el Imperio del Sol y estableciera los cultos a los wak'as, tuvo a Illapa como su awqui, es decir su gemelo o su doble espiritual (Ziólkowski 1984). Y de hecho, no fue por azar que Pachacuti Inka fue retratado en los dibujos de Guaman Poma de Ayala (1989 [1615]: 108) y Murúa ([1590]: Ch. 11) portando los atributos del Rayo.

En la región de Potosí el Rayo fue relacionado igualmente con el nombre de Porco, nombre que, como hemos visto, designa un cerro-wak'a y una mina (Platt et al. 2006: 169-173). Pero el influjo de la divinidad de Porco se extendió más allá del cerro homónimo, conformando una vasta jurisdicción territorial de marcado carácter mineral, 


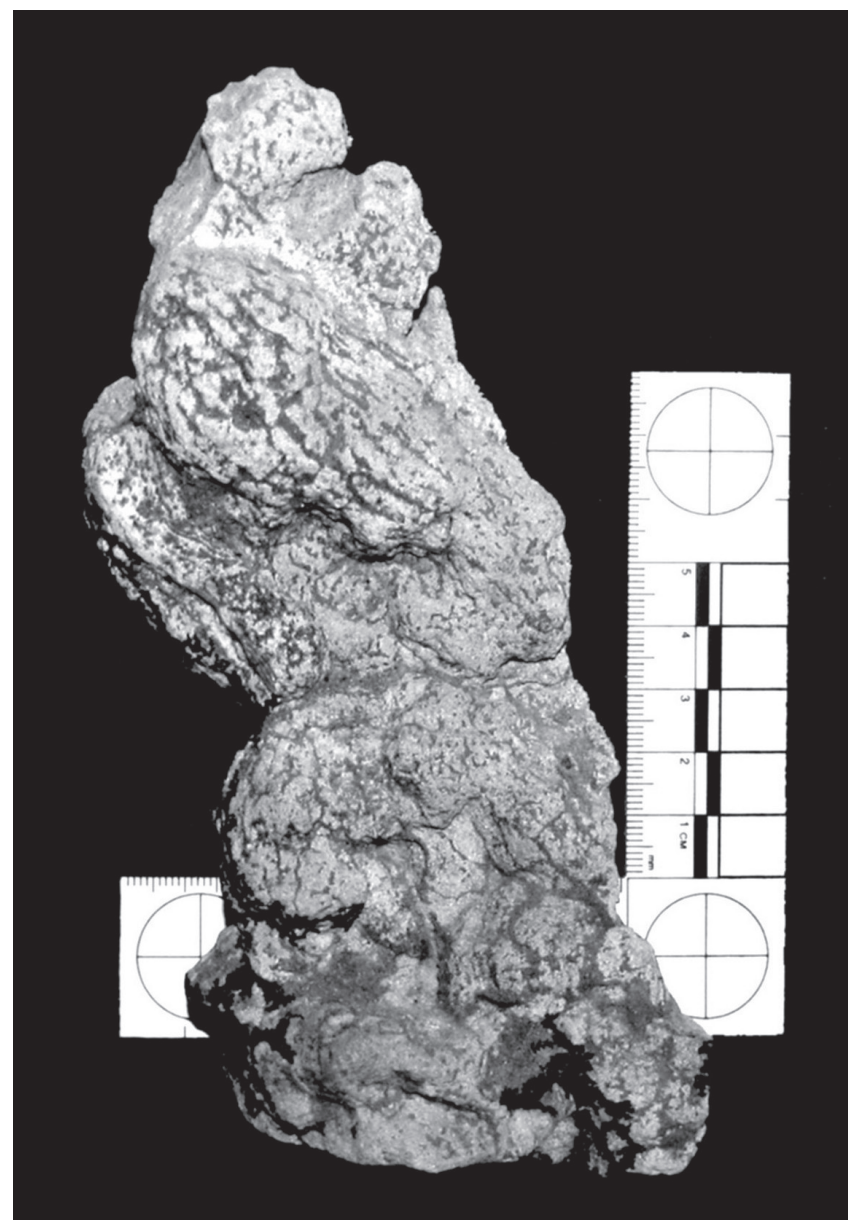

Figura 12. Ylla de mineral de cobre procedente de la mina de Corocoro (2011). Sugestivamente la misma fue identificada como "Tío".

la cual se corresponde con la parcialidad sur del antiguo territorio Qaraqara (Cruz 2009). Aun el nombre del cerro de Potosí se relacionaría con esta divinidad al derivar el mismo del estruendo (potocchi: literalmente "el que revienta"), mediante el cual la montaña se le anunció al Inka Wayna Qhapaq en uno de los mitos de descubrimiento más difundidos; un sonido venido del interior de la tierra semejante al trueno, una de las manifestaciones de la divinidad tripartita del Rayo. Nuevamente las dos versiones más conocidas de la "Virgen del Cerro" hacen referencia a este mito representando al Inka portando los atributos del Rayo, la honda y el proyectil de oro en la mano. De la misma manera, el evento quedaría igualmente plasmado en la toponimia del cerro de Potosí al designar, a lo menos hasta 1783 (plano del cerro, AGI, MP Buenos Aires, 153), bajo el nombre de Wayna Qhapaq (Huayna Capac; hoy
Guanacabra o Guaynacabra) una de las lomas colindantes de la montaña, contigua a la quebrada de Santiago y al Huayna Potosí, el pequeño cerro donde se localizan las minas más antiguas.

Esta jurisdicción territorial vinculada con las fuentes de metal y la divinidad del Rayo no sería la única en esta región de los Andes. Otra jurisdicción establecida por los inkas se habría encontrado en los valles chuquisaqueños situados al este de Potosí, en el área central del antiguo territorio de los yampara. Tal como lo sugiere el agustino Antonio de la Calancha (1978[1638]: 297-301), esta jurisdicción habría estado marcada por un conjunto de 12 cerros sacralizados, todos ellos considerados como fuentes de riqueza mineral, ubicados en torno a la ciudad de Sucre, siendo el más importante del ellos el Apoquiquijana 
(Quiquijana), en cuya cumbre se registró un importante santuario prehispánico (Cruz 2009). Esta jurisdicción se encontraba vinculada con el wak'a de Tangatanga, el cual, como Porco, era una manifestación local de la divinidad prehispánica del Rayo. Representado con una estatua de tres cabezas (Gisbert 2004: 88-89), el adoratorio de este wak'a se encontraba junto a una vertiente de agua a los pies del cerro Churuquella, en el actual barrio de Recoleta de la ciudad de Sucre (Calancha 1638; Abecia 1939: 17). Tal como señala de la Calancha (1978[1638]: 301) el cerro Churuquella era adorado por los indígenas locales “...tanto como porque las tempestades que por alli vienen son terribles con truenos grandes, relanpagos $i$ rayos, como porque dicen que en las entrañas cría rica plata...". De manera significativa, sabemos por los estudios de Del Río y Presta (1984) y Presta (2014), que los inkas establecieron en esta región de Chuquisaca numerosos enclaves de mitmaqkunas, procedentes principalmente del Qollasuyu y del Condesuyu. Finamente, creemos que otras jurisdicciones territoriales marcadas por cerros minerales se habrían encontrado en las regiones de Chicha y Sud-Lípez. ${ }^{21}$

Volviendo a los casos estudiados, en trabajos anteriores hemos señalado la existencia de adoratorios de altura en las cumbres de los principales cerros minerales de la región de Potosí (Cruz 2009). Entre ellos se destacan los adoratorios de los cerros de Porco, Mundo, Lípez (San Antonio) y Cuzco. Es importante tener en cuenta aquí que las características de estos adoratorios (plataformas, recintos, ofrendas de leños, etc.) se corresponden con los denominados santuarios de altura inkaicos, aunque en ninguno de ellos se hallaron restos de sacrificios de capacocha. Salvo el caso de Berenguela de Pacajes, cuya explotación prehispánica fue señalada por el padre Barba (1770[1640]), no se disponen aún de informaciones sobre la existencia de algún adoratorio asociado con las minas. Sobre el cerro de Porco, un documento redactado por el bachiller Hernán González de la Casa (Platt et al. 2006: 182-206), señalaba que allí se encontraba depositado el wak'a del mismo nombre, el cual era venerado y objeto de peregrinación por parte de todas las naciones aymaras de Charcas (Espinoza Soriano 1969: 117-152). A fin de evitar que el wak'a cayera en manos de los españoles, el mismo fue sacado del cerro de Porco y ocultado en el cercano cerro de Caltama, donde finalmente sería extirpado por

${ }^{21}$ Las mismas son actualmente objeto de estudio. el bachiller González de la Casa. Otra referencia sobre el wak'a de Porco, nos conducen al cerro Poder de Dios en el valle de Chaquí referido anteriormente, donde el mismo se habría encontrado al interior de una mina, la cual fue igualmente ocultada de los españoles tapando su entrada (Platt et al. 2006: 215-220). Sobre la cima del cerro Apu Porco, por encima de las minas y del actual poblado, se registraron un conjunto de plataformas, entre las cuales se destaca una en forma de corona que encierra en su interior dos grandes pozos verticales. Se trata muy probablemente de antiguas explotaciones mineras, acondicionadas con muros de contención, permitiendo a uno de ellos superar los $30 \mathrm{~m}$ de profundidad (Cruz 2009: 59). La cumbre del Cerro Rico de Potosí también acogió un adoratorio de altura, aunque los más de cuatro siglos de trabajo ininterrumpido sobre la montaña desvanecieron todo rastro material del mismo. Según un testimonio del propio Diego Guallpa, quien antes de revelar las fabulosas vetas a los españoles oficializó la condenación del adoratorio, en la cumbre del cerro se encontraba una "mesa" de 30 pies de lado (aprox. 8,3 m) donde habrían encontrado depositadas algunas "ofrendas" en plata labrada, en oro y otras "cosas de poca importancia", destinadas al wak'a de Potosí (De la Fuente Sanct Ángel 1965 [1572]: 358-359). Recientemente, esta relación entre adoratorio y mina prehispánica fue nuevamente puesta en evidencia en el cerro Cuzco, distante aproximadamente $75 \mathrm{~km}$ de Porco y $105 \mathrm{~km}$ de Potosí (Cruz et al. 2013). Sobre la cumbre de este cerro, por encima de los $5400 \mathrm{~m}$, se encuentra un adoratorio de altura, compuesto por una plataforma rectangular y varios recintos asociados con un conjunto de explotaciones mineras superficiales. Pero a diferencia de Porco y Potosí, el cerro Cuzco no fue trabajado por los españoles, ni tampoco más tarde, razón por lo cual sus contextos quedaron relativamente bien preservados. No obstante, como sucedió en los dos casos anteriores, el adoratorio del cerro Cuzco habría sido condenado, extrayéndose del mismo todo resto votivo presente en la plataforma y en los recintos, al mismo tiempo que se procuraron ocultar las minas colmatando sus aperturas (Cruz et al. 2013). Finalmente, en cuanto al cerro Lípez, a cuyos pies se localizó el centro de San Antonio del Nuevo Mundo, aparte del adoratorio situado en su cumbre, se destaca en la base del cerro, en cercanía a las minas de Mesa de Plata y al poblado de Wayq'u Seco, un conjunto de al menos 18 rocas exhibiendo diseños serpentiformes que se asemejan a representaciones de rayos, marcando 


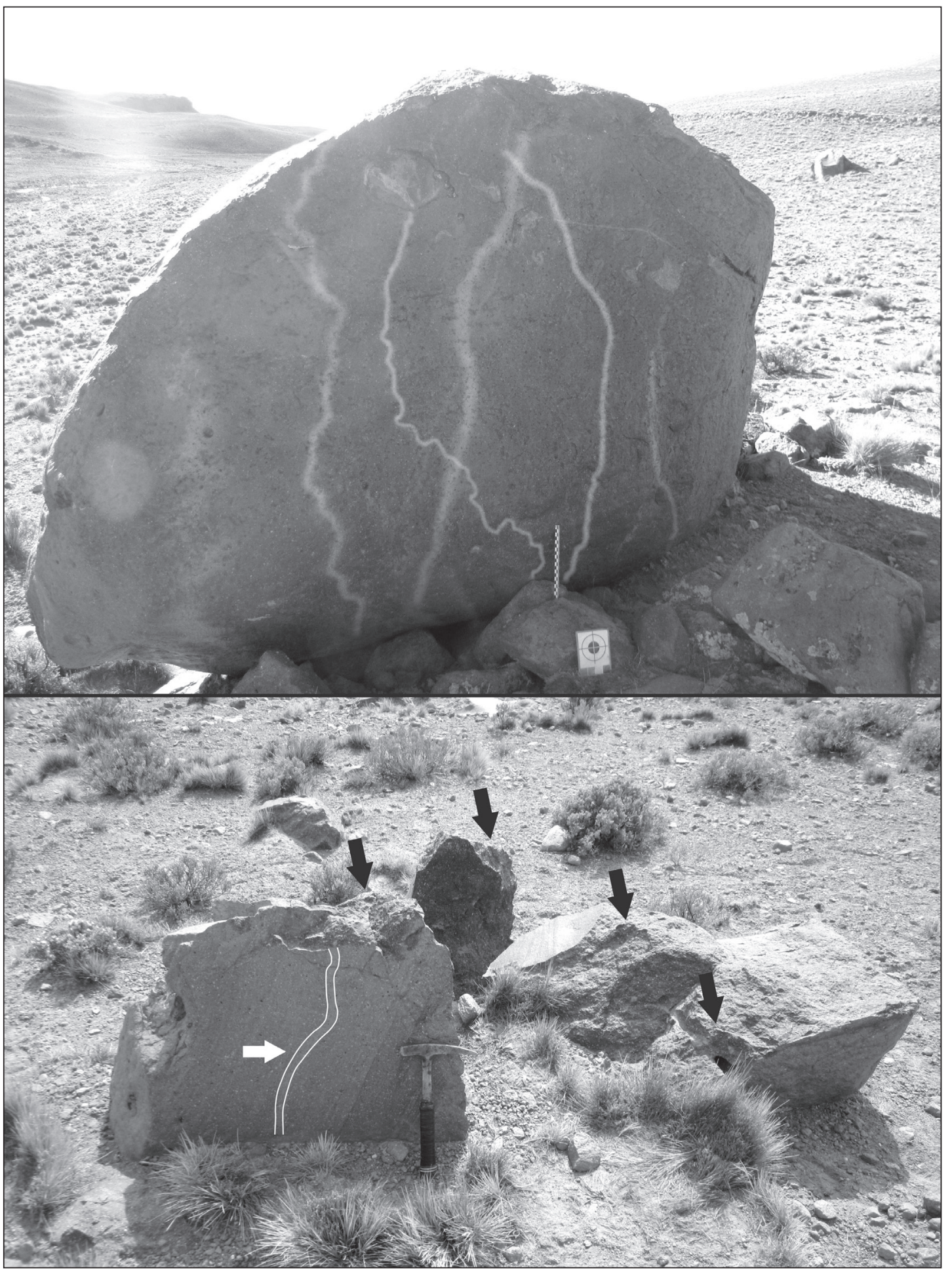

Figura 13. Fotografías de rocas con diseños serpentiformes registradas en San Antonio de Lípez. La de la fotografía inferior fue destruida intencionalmente con golpes de maza y agujeros de barreno, las flechas negras indican los puntos de impacto. 
un trayecto orientado a la cima de la montaña (Figura 13). Prueba de la importancia que tuvieron los antiguos cultos mineros y de lo problemático que los mismos resultaron para la Iglesia, es que varias de estas rocas con diseños serpentiformes fueron parcialmente destruidas o presentan grabados de cruces cristianas. No se trata de un único caso, conjuntos de rocas con diseños semejantes fueron registrados en tres otros importantes cerros-wak'a minerales de la región (cerros Tunupa, Cosuña y Cuzco), aunque en ninguno de ellos se observaron tan fuertes señales de extirpación como en San Antonio (Cruz 2013; Cruz et al. 2013). Significativamente, hoy estas rocas con diseños son denominadas por los pobladores de la región como tatala purita ("ha venido el Señor"), en referencia al Rayo, y evitadas debido a las fuerzas que de ellas emanan.

\section{* Consideraciones finales}

Como ha sido desarrollado anteriormente, tanto las fuentes tempranas como el registro arqueológico subrayan la participación que tuvieron los yanaconas y mitayos principalmente oriundos de las provincias del Collao, en la producción de metales durante los primeros momentos de la Colonia. Ambos registros señalan también que la presencia de éstos qollas en las minas y centros metalúrgicos estuvo en muchos casos, por lo menos hasta las reformas toledanas, bajo un control directo de los inkas, muy probablemente en continuidad con los años que precedieron la Conquista española. El rostro de los mineros qollas se ve reflejado igualmente en el ámbito de la religión, donde los cultos prehispánicos a los wak'as minerales y a los metales confluyeron en torno a la divinidad del Sol, pero también a la del Rayo y la Guerra -y ahora sabemos también los metales-, la cual fue identificada en la región de Potosí bajo el nombre de Porco. Las rocas con diseños que sugieren representaciones de rayos registradas en los cerros Lípez, Cuzco y Tunupa -y que se encontraban vinculadas con las minas- constituyen posiblemente testimonios de los antiguos cultos que los mineros qollas rindieron a esta divinidad. Una razón más que suficiente para que los españoles procuraran destruirlas, o que grabaran cruces cristianas sobre ellas, tal como sucedió en San Antonio del Nuevo Mundo. Hay en este punto un tema que merece ser más explorado y profundizado, a saber en qué medida los cultos al Sol y al Rayo en el ámbito de la minería no estarían reflejando las tensiones que volvieron a surgir entre los inkas del Cuzco y los propios pobladores del Qollasuyu durante los primeros años de la Colonia.

A pocos años de su fundación, la Villa Imperial de Potosí se había convertido ya en el motor de la empresa colonial en los Andes, pero también en un nuevo Cuzco para una fracción de la élite inkaica que consideró, con justeza, que la posición privilegiada de sus miembros se encontraba ligada a su participación en la producción de los metales. Sin embargo, su situación cambiaría de manera radical durante los primeros años de la década de 1570 en razón de la claudicación de la resistencia de Vilcabamba, la aplicación de las Ordenanzas del Virrey Toledo, y -por sobre todo- el remplazo de los hornos indígenas por la nueva tecnología de amalgamación. No obstante la caída en desgracia de los inkas, los yanaconas y mitayos qollas continuaron prestando sus brazos en las minas y en los nuevos ingenios de Potosí, participando activamente, incluso, en el descubrimiento de nuevas minas tras la caída del mineral del Cerro Rico. De suerte que, por lo menos en los ámbitos de la minería y de la producción de metales, la conquista española y el derrumbe del Imperio del Sol significaron para los pobladores del Collao la apertura de un espacio de negociación más favorable dentro del nuevo orden colonial. Es en este nuevo escenario para los qollas que Francisco Tito Yupanqui, descendiente directo de Paullu Inka, quien fuera coronado durante la conquista como soberano del Qollasuyu (Medinacelli 2007) y se habría mantenido cercano a los españoles, crea en Potosí una estatua de la virgen de la Candelaria destinada a la iglesia de Copacabana. Esta localidad, un importante centro de culto prehispánico situado al borde del Titicaca, congregaba por entonces a la élite qolla e inka del Collao (Del Río 2009). Una vez concluida la estatua de la virgen en Potosí, esta fue transportada hasta Copacabana por el propio Francisco junto a otros dos descendientes de la élite inka del Collao. Se trataba de Alonso Wiraqucha Inga y de Pablo de Cáceres Challco Yupanqui, hijos de Baltazar Challco Yupanqui, quien habría participado en la entrega del cerro de Potosí a los españoles (Platt y Quisbert 2008), y nietos de Apo Challco Yupanqui quien fuera, en tiempos del Inka, sacerdote del Sol y Gobernador del Qollasuyu. Este evento de marcado carácter religioso no solamente nos señala los estrechos vínculos existentes entre Potosí y 
Copacabana en torno a las minas surandinas, sino también la posición de las antiguas élites dentro del nuevo orden colonial y cristiano.

Aunque con el transcurrir del tiempo la participación de los pobladores del Collao en las minas e ingenios surandinos fue menguando de manera progresiva, ella nunca dejó de ser significativa. Durante los siglos venideros los mineros qollas continuaron migrando a los nuevos centros mineros, estableciendo colonias permanentes en muchos de ellos y conformando una diáspora que garantizaría el remplazo y el nuevo suministro de mano de obra especializada. Tal fue el caso, por ejemplo, de las comunidades Machaqas que se conformaron cerca de Potosí a raíz de los vínculos tejidos en torno a la mina entre Pacajes y la Villa Imperial durante varios siglos de mita (Choque Canqui 2003: 200-203). Otro testimonio resultante de estas migraciones prolongadas en el tiempo y vinculadas con el laboreo de las minas se encuentra en la multiplicidad de apellidos procedentes del Collao presentes en otras regiones mineras, como es el caso en la puna de Jujuy. Su presencia también se refleja en la continuidad y en la reproducción de un particular carácter religioso del mundo de la mina, a lo menos desde el Collao hasta el norte argentino, donde las siluetas diabólicas del Tío se erigen hoy como soberanos absolutos en los socavones de las principales minas.

En 1881, Luis Brackebush, un alemán erudito en minería, acompañado por Teófilo Sánchez de Bustamante, por entonces ex-Gobernador de la provincia de Jujuy, visitaron una pequeña mina de plata situada en el cerro Mudana, cerca de la localidad de Huacalera en la Quebrada de Humahuaca. Según nos cuenta Brackebush, antes de abrir un nuevo paraje de trabajo, los mineros de allí tenían la costumbre de colocar una piedra de cuarzo, a la cual ponían por encima una pequeña cruz, en el lugar mismo donde se iniciarían las labores. Congregados alrededor de la piedra, los mineros se inclinaban ante la misma en son de reverencia y le ofrendaban sus acullicus y libaciones de chicha y aguardiente. En sus palabras, la ceremonia culminaba "con una total ebriedad de los religiosos mineros, que al fin quedan acostados alrededor de su Pachacamak, con cuyo nombre bautizan la piedra blanca con la crucecita" (Brackebush 1991 [1883]: 36). Pocas dudas quedan, a pesar de la distancia, del origen qolla de estos devotos mineros indígenas.

\section{$*$ Referencias citadas}

ABECIA, N. 1939. Historia de Chuquisaca. Con una Monografía contemporánea de Nicanor Mallo y Faustino Suárez. Editorial Charcas, Sucre.

ABSI, P. 2005. Los ministros del Diablo. PIEB-IRD, La Paz.

ALBARRACÍN-JORDÁN, J. 1996. Tiwanaku: Arqueología Regional y Dinámica Segmentaria. Plural Editores, La Paz.

ALBORNOZ, C. de. [1582]. Instrucción para descubrir todas las guacas del Pirú y sus camayos y haziendas. En P. Duviols, Un inédit de Cristóbal de Albornoz: La instrucción para descubrir todas las guacas del Pirú y sus camayos y haziendas. Journal de la Société des Américanistes 56 (1): 7-39.

ALCOBAZA, D. de (atribuido). 1603. Confessionario para los curas de Indios: Con la instrucion contra sus ritos: y exhortacion para ayudar a bien morir, y summa de sus priuilegios: y forma de impedimentos del matrimonio. Concilio Provincial de 1583. Impreso en casa de Clemente Hidalgo, Sevilla. http://archive.org/details/confessionariopaolcath

ANÓNIMO, 1548. Memoria exacta i completa de los repartimientos de esta ciudad del Cuzco asi vacos como los que tienen dueños. En Documentos para la historia del Perú. Alardes y derramas. Por Rafael Loredo del Instituto Histórico del Perú. GIL S.A. Impresores, Lima.

ANGIORAMA, C. y F. BECERRA. 2010. Antiguas evidencias de minería y metalurgia en Pozuelos, Santo Domingo y Coyahuayma (Puna de Jujuy, Argentina). Boletín del Museo Chileno de Arte Precolombino 15(1): 81-104, Santiago.

ARCE BURGOA, O. y R. GOLDFARB. 2009. Metallogeny of Bolivia. Society of Economic Geologists Newsletter 79: 7-15. Littleton. 
ARZÁNS de ORSÚA y VELA, B. de. 1965 [1737]. Historia de la villa imperial de Potosí. L. Hanke y G. Mendoza (Eds.). Brown University bicentennial publications. The University of Michigan, Michigan.

AVENDAÑO, F. de. 1648. Sermones de los misterios de nuestra Santa Fe Católica, en lengua castellana, y la general del Inca. Impreso por Jorge López de Herrera, Lima. Copia digital en: The John Carter Brown Library.

BAKEWELL, P. 1988. Silver and Entrepreneurship in Seventeenth-Century Potosí, the Life and Times of Antonio López de Quiroga. University of New Mexico Press, Albuquerque.

BANDY, M. 2001. Population and History in the Ancient Titicaca Basin. Ph.D. Dissertation, Department of Anthropology. University of California, Berkeley. http://citeseerx.ist.psu.edu/viewdoc/down load?doi=10.1.1.113.5003\&rep=rep1\&type $=$ pdf

BANDY, M. y J. JANUSEK. 2005. Settlement Patterns, Administrative Boundaries, and Internal Migration in the Early Colonial Period. En Avances en la Arqueología de la Cuenca del Titicaca I, pp. 267-288. C. Stanish, A. Cohen y M. Aldenderfer (Eds.), Cotsen Institute of Archaeology Press, Los Angeles.

BARBA, Á. 1770 [1640]. Arte de los metales. Imprenta del Reyno, Madrid. Copia digital en: Biblioteca El Dorado. Archivo y Bibliotecas Nacionales de Bolivia, Sucre.

BERTHELOT, J. 1978. L'exploitation des métaux précieux au temps des Incas. Annales (ESC), T. 33, 5-6. París.

BETANZOS, J. de. 1987 [1551]. Suma y narración de los incas. Rubio, M. (Ed.). Atlas, Madrid.

BOUYSSE-CASSAGNE, T. 1987. La identidad Aymara. HisbolIFEA, La Paz.

2004. El sol de adentro: Wakas y santos en las minas de Charcas y en el lago Titicaca (siglos XV a XVII). Boletín de Arqueología PUCP 8: 59-97, Lima.

2005. Las minas del centro-sur andino, los cultos prehispánicos y los cultos cristianos. Bulletin de l'IFEA 34.3: 443-462, Lima.

2008. Minas del sol, del Inka y de la gente. Potosí en el contexto de la minería prehispana. En Minas y Metalurgias en los Andes del Sur, entre la época prehispánica y el siglo XVII, Cruz, P. y J. Vacher (Eds.), pp. 278-301. IFEA-IRD, Sucre.
2010. Apuntes para la historia de los puquinahablantes. Boletín de Arqueología PUCP 14: 283-307, Lima.

BOUYSSE-CASSAGNE, T. y P. BOUYSSE. 2006. Montagnes de feu, montagnes sacrées. Archives ouvertes HAL-SHS. Centre pour la Communication Scientifique Directe, CNRS, París. http://halshs.archives-ouvertes.fr/docs/oo/o6/oo/81/PDF/ Autre.pdf

BRACKEBUSH, L. 1991 [1883]. Por los caminos del Norte. Colegio de Graduados en Ciencias Geológicas de Tucumán, Tucumán.

CALANCHA, A. de la. 1978 [1638]. Corónica Moralizadora de la Orden de San Agustín en el Perú. Crónicas del Perú, Prado Pastor I. (Ed.). Universidad Mayor de San Marcos, Lima.

CAPOCHE, L., 1959 [1585]. Relación general de la Villa Imperial de Potosí. Biblioteca de Autores Españoles, Madrid.

CERRÓN PALOMINO, R. 2010. Contactos y desplazamientos lingüísticos en los Andes centro-sureños: el puquina, el aimara y el quechua. Boletín de Arqueología PUCP 14: 255-282, Lima.

CHOQUE CANQUI, R. 2003. Jesús de Machaqa: la marka rebelde. Cinco siglos de historia. CIPCA - Plural Editores, La Paz.

COBO, B. 1964 [1653]. Historia del Nuevo Mundo. Biblioteca de Autores Españoles. Atlas, Madrid.

CRUZ, P. 2009. Huacas olvidadas y cerros santos. Apuntes metodológicos en torno a la cartografía sagrada en los Andes del sur de Bolivia (Potosí, Chuquisaca). Estudios Atacameños 38: 55-74, San Pedro de Atacama.

2010. Tumbas, metalurgia y complejidad social en un páramo del altiplano surandino. Pulacayo, Bolivia, primer milenio d. C. Revista Andina 49: 71-104. Centro Bartolomé de las Casas, Cuzco.

2013. La piedra herida. Reflexiones metodológicas en torno de un establecimiento minero del altiplano surandino. En Los Estudios andinos hoy. Práctica intelectual y estrategias de investigación, C. Zanolli (Comp.), pp. 55-78. Instituto de Ciencias Antropológicas, F.F y L., UBA, Buenos Aires.

CRUZ P. y P. ABSI. 2008. Cerros ardientes y huayras calladas Potosí antes y durante el contacto. En Mina y Metalurgia en los Andes del Sur. Desde la Época Prehispánica hasta el Siglo XVII, P. Cruz y J. Vacher(Eds.), pp. 91-121, IRD-IFEA, Sucre. 
CRUZ P., E. CRUBEZY y P. GERARD. 2013. Los adoratorios de altura inkaicos: una mirada desde el cerro Cuzco, departamento de Potosí, Bolivia. Memoria Americana 21-1. Univ. Nacional de Buenos Aires. Buenos Aires. http://www.scielo.org.ar/scielo. php?script $=$ sci_arttext\&pid $=$ S $185137512013000100004 \& \operatorname{lng}$ $=$ es\&nrm $=$ iso

CRUZ, P. E I. GUILLOT. 2010. Terra Argéntea. Los reinos de metales prehispánicos en el cruce de la Historia y la Arqueología. Surandino Monográfico $\mathrm{N}^{\circ}$. Universidad de Buenos Aires, Buenos Aires. http://www.filo.uba.ar/contenidos/investigacion/institutos/ravignani/prohal/SM_OO4_INFORMES DE_INVESTIGACION/informes.html

DAUESLBERG, P. 1960. Contribución al estudio de la arqueología del valle de Azapa. En Antiguo Perú: espacio y tiempo. R. Matos (Ed.), pp. 273-296. Mejía Baca, Lima.

DEL RÍO, M. 2009. De sacerdotes del Tawantinsuyu a cofrades coloniales: nuevas evidencias sobre los Acustupa y Viracocha Inga de Copacabana. Revista Andina 49: 9-69. Centro Bartolomé de las Casas, Cuzco.

DEL RÍO, M. y A. M. PRESTA. 1984. Un estudio etnohistórico en los corregimientos de Tomina y Amparaez: casos de multietnicidad. Runa XIV: 221-246, Buenos Aires

DEMAREST, A. 1981. Viracocha. Peabody Museum of Archaeology and Ethnology. Harvard University, Cambridge.

ESCOBARI de QUEREJAZU, L. 2011. Mano de obra especializada en los mercados coloniales de Charcas. Bolivia, siglos XVIXVII, Nuevo Mundo Mundos Nuevos. Debates. Mascipo, París. http://nuevomundo.revues.org/60530

ESPINOZA SORIANO, W. 1969. El Memorial de Charcas: crónica inédita de 1582. Cantuta: 117-152. Ediciones de la Universidad Nacional de Educación, Chosica.

1972. Copacabana del Collao. Un documento de 1548 para la etnohistoria andina. Bulletin de l' IFEA I N ${ }^{\circ}$ 1: 1-16, Lima.

FRYE, K. y E. de la VEGA. 2005. The Altiplano Period in the Titicaca Basin. En Advances in Titicaca Basin Archaeology I. C. Stanish, A. Cohen y M. Aldenderfer (Eds.), pp. 173-184. Cotsen Institute of Archaeology Press, Los Angeles.

FUENTE SANCT ÁNGEL, R. de la. 1965 [1572]. Relación del cerro de Potosí y su descubrimiento. En Relaciones geográficas de Indias
Vol. II, M. Jiménez de la Espada (Comp.), pp. 357-361. Biblioteca de Autores Españoles, Madrid.

GISBERT, T. 2004. Iconografía y mitos indígenas en el arte. Gisbert y Cía, La Paz.

GONZÁLEZ, L. 2004. Bronces sin nombre. La metalurgia prehispánica en el Noroeste Argentino. Ediciones Fundación CEPPA, Buenos Aires.

GUAMAN POMA de AYALA, F. 1989 [1615]. Nueva corónica y buen gobierno. Institut d'Ethnologie, edición facsimil, París. (1615/1616) København, Det Kongelige Bibliotek, GKS $22324^{\circ}$. http://www.kb.dk/permalink/2006/poma/335/es/ text/?open $=$ \&imagesize $=\mathrm{XL}$

HERNÁNDEZ PRÍNCIPE, R. 1923 [1621]. Mitología Andina. Idolatrías en Recuay. Revista Inca 1 (1): 25-78, Lima.

HYSLOP, J. 1976. An Archaeological Investigation of the Lupaqa Kingdom and its Origins. Tesis doctoral, Departamento de Antropología, Columbia University, New York.

JIMÉNEZ de la ESPADA, M. 1885. Relaciones Geográficas de Indias, Perú. Tomo II, Madrid.

JULIEN, C. 1983. Hatunqolla: A View of Inca Rule from the Lake Titicaca Region. Series Publications in Anthropology 15. University of California Press, Berkeley. 2004. Hatunqolla. Producciones CIMA. La Paz.

LECHTMAN, H. 1978. Temas de metalurgia Andina. Tecnología Andina Ravines, R. (Comp.): 489-520. Instituto de Estudios Peruanos, Lima.

LECHTMAN, H., P. CRUZ, A. MacFARLANE y S. CARTER. 2012. Procesamiento de metales durante el Horizonte Medio en el Altiplano surandino (Escara, Pulacayo, Potosí). Boletín del Museo Chileno de Arte Precolombino 15/ 2: 9-27. Santiago.

LEVILLIER, P. 1922. Carta a S.M. de los Licenciados Cepeda Lopidana, 31 de diciembre de 1586. Audiencia de Charcas. Correspondencias de Presidentes y Oidores. Documentos del Archivos de Indias. Biblioteca del Congreso Argentino. Imprenta Juan Pueyo, Madrid.

LOZANO MACHUCA, J. 1992 [1581]. Carta del Factor de Potosí... al Virrey del Perú, en donde se describe la Provincia de los Lípez. Potosí, 8 de Noviembre de 1581. Estudios Atacameños 11: 30-34, San Pedro de Atacama. 
MEDINACELLI, X. 2007. Paullu y Manco ¿una diarquía inca en tiempos de conquista? Bulletin de l'IFEA 36 (2): 241-258. Lima

MICHEL LÓPEZ, M. 2011. El Señorío prehispánico de Carangas. Tesis. Universidad de la Cordillera, La Paz. Copia digital en: Saberes Bolivianos. http://www.saberesbolivianos.com/investigadores/Michel/CarangasMMichel.pdf

MILLONES, L. 1982. Brujerías de la Costa / Brujerías de la Sierra: estudio comparativo de dos complejos religiosos en el área andina. En El Hombre y su Ambiente en los Andes Centrales. L. Millones y H. Tomoeda (Eds.), pp. 229-274. Senri Ethnological Studies, Lima.

MUNIZAGA, C. 1957. Secuencias culturales de la zona de Arica (comparación entre las secuencias de Uhle y Bird). EnArqueología chilena. Contribución al estudio de la región comprendida entre Arica y La Serena. R. Schaedel (Ed.), pp. 77-122. Universidad de Chile, Santiago.

MUÑOZ, I. y J. CHACAMA. 1988. Cronología por termoluminiscencia para los períodos Intermedio Tardío y Tardío en la sierra de Arica. Chungara 20: 19-45, Arica.

MURÚA, M. de. 1961[1613]. Historia general del Perú, origen y descendencia de los incas. Joyas Bibliográficas, Manuel Ballesteros-Gaibrois, Madrid.

(2004 [1590]). Códice Murúa: Historia y Genealogía de los Reyes Incas del Perú del Padre Mercenario Fray Martín de Murúa: Códice Galvin. J. M. Ossio A. (Ed). Testimonio Compañía Editorial, Madrid.

NIEMEYER, H. y V. SCHIAPPACASSE. 1981. Aportes al conocimiento del período Tardío del extremo norte de Chile: análisis del sector Huancarane del valle de Camarones. Chungara 7:3-104, Arica.

OCAÑA, D. de. 1969 [1605]. Relación de un viaje por América. Fray Arturo Álvarez, Studium, Madrid.

PÄRSSINEN, M. y A. SIIRIÄNEN. 1997. Inka-Style Ceramics and their Chronological Relationship to the Inka Expansion in the Southern Lake Titicaca Area (Bolivia). Latin America Antiquity 8 (3): 255-271.
PAUWELS, G. 1999. Oruro 1607, Informe de Felipe de Godoy. Eco Andino Año 4, N 7-8: 87-172. CEPA, Oruro.

PLATT, T.; T. BOUYSSE-CASSAGNE y O. HARRIS. 2006. Qaraqara-Charka. Mallku, Inka y Rey en la provincia de Charcas (Siglos $X V-X V I I)$. La Paz: Historia antropológica de una confederación aymara. IFEA, Plural, University of St. Andrews, University of London, Inter American Foundation y FCBCB.

PLATT, T. y P. QUISBERT. 2008. Sobre las huellas del silencio: Potosí, los Incas y el Virrey Francisco de Toledo (siglo XVI). En Minas y Metalurgias en los Andes del Sur, entre la época prehispánica y el siglo XVII. P. Cruz y J. Vacher (Eds.), pp. 231-277. IFEA-IRD, Sucre.

PRESTA, A. M. 2014. Los valles mesotérmicos de Chuquisaca. Entre la fragmentación territorial yampara y la ocupación de los migrantes altiplánicos en la temprana Colonia. En QaraqaraCharka Tres Años Después. A. M. Presta (Ed.). IFEA-PLURAL. La Paz. (En prensa).

RAFFINO, R. 1993. Inka: arqueología, historia y urbanismo del altiplano andino. Corregidor, Buenos Aires.

SÁNCHEZ ALBORNOZ, N. 1994. La población de América Latina: desde tiempos precolombinos al año 2025. Alianza Editorial, Madrid.

SAIGNES, T. 1981. Des Lupacas dans les vallées orientales des Andes: trajets spaciaux et repères démographiques (XVIXVII siècles). Mélanges de la Casa de Velázquez, T. 17: 147-182, Madrid.

1985a. Potosí et le sud bolivien selon une ancienne carte. Caravelle - Cahiers du monde hispanique et luso-brésilien, Vol. $44 \mathrm{~N}^{\circ}$ 44: 123-128. Institut pluridisciplinaire pour les études sur les Amériques, Toulouse.

1985b. Caciques, Tribute and Migration in the Southern Andes: Indian Society and the 17th Century Colonial Order (Audencias de Charcas). ISA Occasional Papers, Institute of Latin American Studies, University of London, Londres.

SCHIAPPACASSE, V.; Á. ROMAN e I. MUÑOZ. 1991. Cronología por termoluminiscencia de la cerámica del extremo norte de Chile. Actas del XI Congreso Nacional de Arqueología Chile (1988), Primera parte, tomo II, pp. 43-6o. Museo Nacional de Historia Natural, Santiago. 
STANISH, C.; E. de la VEGA, L. STEADMAN, C. CHÁVEZ JUSTO, K. FRYE, L. ONOFRE MAMANI, M. SEDDON y P. CALISAYA CHUQUIMIA. 1997. Archaeological Survey in the JuliDesaguadero Region of the Lake Titicaca Basin, Southern Peru. Fieldiana Anthropology, Field Museum Press, Chicago.

TÉREYGEOL, F. y P. CRUZ. 2011. Huayrachina - Ein Schmelzofen für nicht eisenhaltige Melallerze aus den Anden. En Schätze der Anden, chiles kupfer für die welt, pp. 265-268. Bochum.

TSHOPIK, M., 1946. Some notes on the archaeology of the Department of Puno, Peru. The Museum, Cambridge.

VAN BUREN, M. y C. COHEN. 2010. Technological changes in silver production after the spanish conquest in Porco, Bolivia. Boletín del Museo Chileno de Arte Precolombino 15(2): 29-46. Santiago.

WACHTEL, N. 1989. Les transformations de Tunupa. Restructurations religieuses dans les Andes méridionales (XVIe-XVIIe siècles). Mélanges de l'Ecole française de Rome. Italie et Méditerranée. Tomo 101, N²: 839-873, Roma.
ZIÓLKOWSKI, M. 1984. La piedra del cielo: algunos aspectos de la educación e iniciación religiosa de los príncipes incas. Antropológica T. II: 45-65, Lima.

\section{Fuentes manuscritas citadas}

ANÓNIMO, siglo XVII. Mapa titulado: "La province de Potosi dans le Haut-Pérou". Biblioteca Nacional de Francia, BNF, GE DD2983.

CABRERA, G. de. 1571. Orden que se dio en Potosí para que los indios no hiciesen fundiciones de plata y nombramientos de alcaldes que se hicieron en varias doctrinas. Biblioteca Nacional de España, BN, 3040 fs. 167r-169v.

LIZARAZU, J. de. 1635. Cartas de Audiencia. Archivo General de Indias, AGI, Charcas, 20, R. 14, N. 161.

MALDONADO de TORRES, A. 1606. Carta del Lic. Alonso Maldonado de Torres, Presidente de la Audiencia de Charcas. AGI, Charcas 18 R.3 N.2O. 